\title{
Thalamic neuromodulation and its implications for executive networks
}

\author{
Carmen Varela* \\ Picower Institute for Learning and Memory, Massachusetts Institute of Technology, Cambridge, MA, USA
}

\section{Edited by:}

Guillermo Gonzalez-Burgos,

University of Pittsburgh, USA

\section{Reviewed by:}

Robert P. Vertes, Florida Atlantic University, USA

Randy M. Bruno, Columbia University, USA

\section{*Correspondence:}

Carmen Varela, Picower Institute for Learning and Memory, Massachusetts Institute of Technology, Building 46, Room 5233, 43 Vassar Street, Cambridge, MA 02139, USA e-mail: carmenv@mit.edu
The thalamus is a key structure that controls the routing of information in the brain. Understanding modulation at the thalamic level is critical to understanding the flow of information to brain regions involved in cognitive functions, such as the neocortex, the hippocampus, and the basal ganglia. Modulators contribute the majority of synapses that thalamic cells receive, and the highest fraction of modulator synapses is found in thalamic nuclei interconnected with higher order cortical regions. In addition, disruption of modulators often translates into disabling disorders of executive behavior. However, modulation in thalamic nuclei such as the midline and intralaminar groups, which are interconnected with forebrain executive regions, has received little attention compared to sensory nuclei. Thalamic modulators are heterogeneous in regards to their origin, the neurotransmitter they use, and the effect on thalamic cells. Modulators also share some features, such as having small terminal boutons and activating metabotropic receptors on the cells they contact. I will review anatomical and physiological data on thalamic modulators with these goals: first, determine to what extent the evidence supports similar modulator functions across thalamic nuclei; and second, discuss the current evidence on modulation in the midline and intralaminar nuclei in relation to their role in executive function.

\section{Keywords: modulators, acetylcholine, serotonin, dopamine, noradrenaline, histamine, midline, intralaminar}

\section{INTRODUCTION AND KEY TERMS THALAMIC AFFERENTS: DRIVERS AND MODULATORS}

All the forebrain structures that contribute to cognitive functions receive input from the thalamus, which is a critical point for the routing of information and gateway control. Thalamic cells receive two general types of afferents, drivers and modulators. Thalamic drivers are afferents that target proximal dendrites with relatively large synaptic boutons, reliably evoke spikes in thalamic cells, and whose function is thought to be the faithful transmission of the spike message relayed by thalamic cells to postsynaptic structures. In contrast, modulators are those afferents that target primarily distal dendrites and influence spike transmission by adjusting the cellular and synaptic mechanisms underlying spike generation; by doing so, they are thought to fine-tune the message relayed by thalamic cells and control its probability of transmission (reviewed in Sherman and Guillery, 1998; Guillery and Sherman, 2002). It should be noted that this distinction between drivers and modulators is largely based on evidence from the sensory thalamus, which has critical relay functions. Outside of the sensory thalamus, the evidence (still scarce and mostly anatomical) suggests that the anatomical features that distinguish drivers and modulators are present in all thalamic nuclei, although the functional correlates regarding spike generation and transmission still need to be characterized for many thalamic regions. For example, nuclei outside the primary sensory thalamus receive afferents with driver morphology from multiple sources (Baldauf et al., 2005; Masterson et al., 2009). These drivers converging onto individual cells may contribute to spike generation like the drivers in sensory thalamus, but each of them could also contribute to subthreshold modulation that is integrated across all drivers to generate an output, something that will need to be tested. Similarly, some modulators outside of the primary sensory thalamus share features of drivers (such as the large cholinergic afferents in some higher order nuclei, reviewed below). Therefore, the definition of drivers and modulators that is used here is an operational definition that may need refinement as we learn more about the thalamus.

In every thalamic nucleus studied to date, modulator synapses are found to constitute the vast majority of inputs to a given relay cell. The innervation by modulators is particularly dense in the midline and intralaminar groups of thalamic nuclei, both interconnected with executive areas such as the medial prefrontal cortex (mPFC) and basal ganglia. mPFC and the basal ganglia have been extensively studied, including the effect of modulators on these regions. Surprisingly, the midline and intralaminar nuclei are largely unexplored territory compared to neocortex, basal ganglia, or the sensory thalamic nuclei. Even some basic questions, such as the cell response properties or the modulator effects on these thalamic nuclei, remain unanswered. This review will first discuss anatomical and physiological results on modulators across the thalamus. In the second part, it will review recent evidence that highlights the importance of midline and intralaminar nuclei in executive functions, and the role of modulators in these nuclei. The objective is to point out important gaps in knowledge and untested hypotheses regarding the function of modulators in the thalamus. Recent technological developments (optogenetics, pharmacogenetics, clearing techniques such as "clarity") provide powerful 
tools to address many open questions that must be answered in order to elucidate the role of thalamic modulation in executive networks.

Modulators constitute a heterogeneous group of afferents that nevertheless share some anatomical and physiological properties across the thalamus (reviewed in Sherman and Guillery, 1998; Figure 1A). Modulators originate in a variety of brain regions and use various neurotransmitters (summarized schematically in Figure 1B). Examples of thalamic modulators include cholinergic, serotonergic, dopaminergic, and noradrenergic afferents from the brainstem, histaminergic afferents from the hypothalamus, and glutamatergic afferents from layer VI of neocortex.

The first part of this review will discuss the anatomy and physiology of six chemically defined modulators across the thalamus. GABAergic inputs to thalamic nuclei, which originate primarily from diencephalic sources, will not be considered in this review. Furthermore, many neuroactive peptides (including orexins) co-localize with neurotransmitter systems in the thalamus (reviewed in Jones, 2007), and can have wider effects than neurotransmitters, for example, on gene expression, synaptogenesis, local blood flow, etc. Because of their broad spectrum of actions they fall far from the scope of this review. Similarly, other unconventional neurotransmitters like endocannabinoids, purines, and nitric oxide are present in the terminals of some thalamic afferents (reviewed in Jones, 2007), but their effects will not be examined here.

\section{THALAMIC NUCLEI: FIRST AND HIGHER ORDER}

Guillery (1995) distinguished two groups of thalamic nuclei: "First order" are those nuclei that receive drivers from ascending afferent pathways, and transmit information that arrives at the thalamus for the first time. Nuclei in the other group were named "higher order," and are those that relay information that has gone through the thalamus at least once (through a first order nucleus). The main feature that distinguishes higher from first order nuclei is that at least some of their driver input originates in layer $\mathrm{V}$ of neocortex; for this reason, they are thought to participate in cortico-cortical communication (Theyel
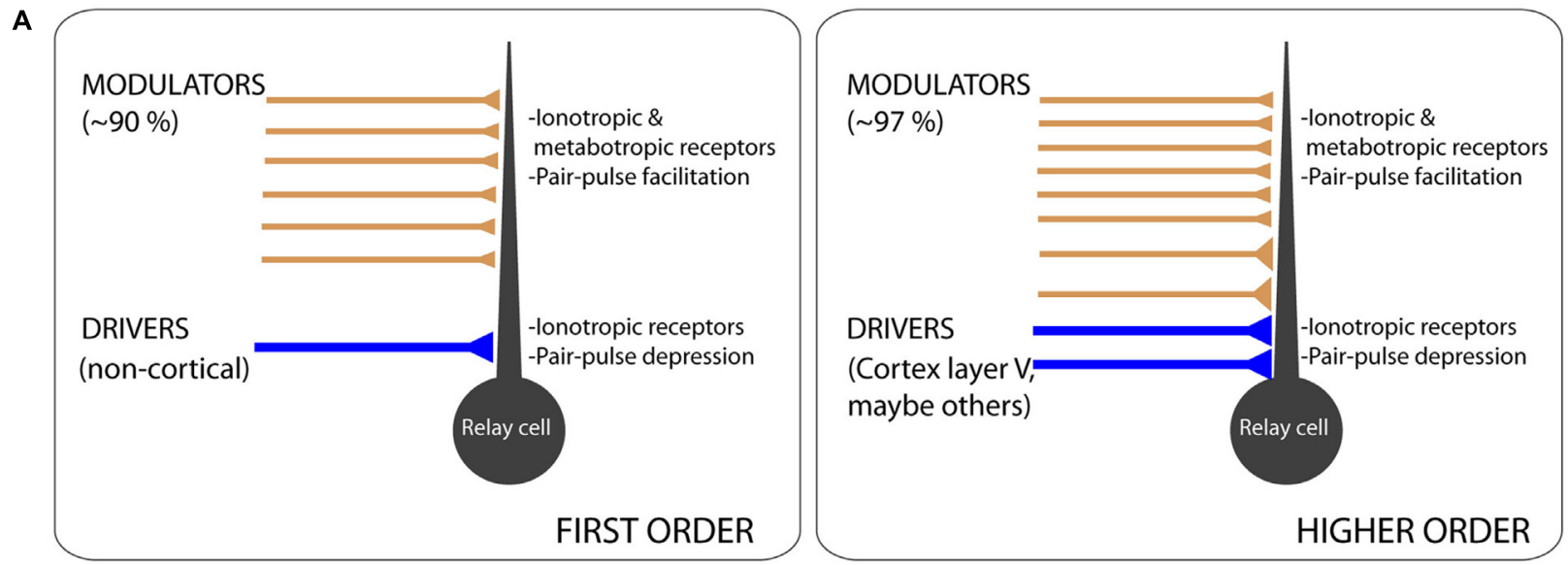

B

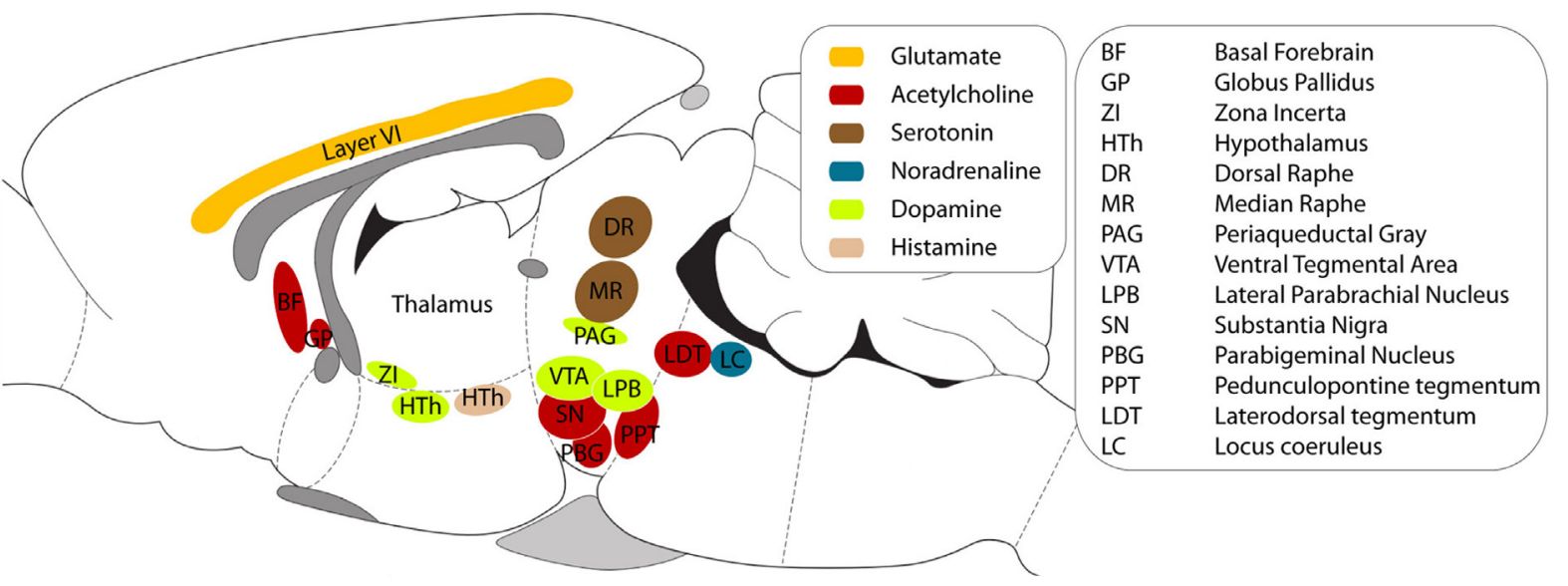

FIGURE 1 | General properties of thalamic afferents. (A) Schematic representation of the features that distinguish drivers and modulators in first order (left) and higher order (right) nuclei. Note the higher fraction of modulators in higher order nuclei, where some modulators have large synapses contacting proximal dendrites. In both first and higher order nuclei, modulators activate ionotropic and metabotropic receptors and, in those in which it has been tested, the postsynaptic responses facilitate under repetitive stimulation. (B) Approximate location of the brain regions that provide modulator afferents to the thalamus, color-coded for the neurotransmitter they use. The outline of a rodent brain is used for convenience, although the diagram combines results from different species (see text for details). 
etal., 2010). The first order group includes the ventral posterior, the ventral part (parvocellular) of the medial geniculate nucleus, the dorsal lateral geniculate nucleus (LGN), and the anterior thalamic nuclei, which receive somatosensory, auditory, visual, and mammillary afferents, respectively. There is evidence of layer $\mathrm{V}$ neocortical input for most of the other thalamic nuclei. These higher order nuclei have projections to higher order cortical regions (Clascá et al., 2012) and accumulating evidence points to the role of these nuclei in cognitive processes. See Figure 2 for a schematic representation of thalamic nuclei at three anteroposterior levels of the rat thalamus, color-coded to indicate the first or higher order nature of each nucleus.

Modulators contribute a large proportion of the synapses that thalamic cells receive, their axonal terminals have thin and diffuse branches, and their terminals contain round small vesicles (they are called RS terminals, for their "Round" vesicles and "Small" size). Most RS terminals (the typical modulator morphology) contact the distal and intermediate parts of the dendrites. In cells reconstructed from thalamic first order nuclei, RS terminals form $40-80 \%$ of the synapses in distal and intermediate dendrites (Wilson etal., 1984; Raczkowski et al., 1988;

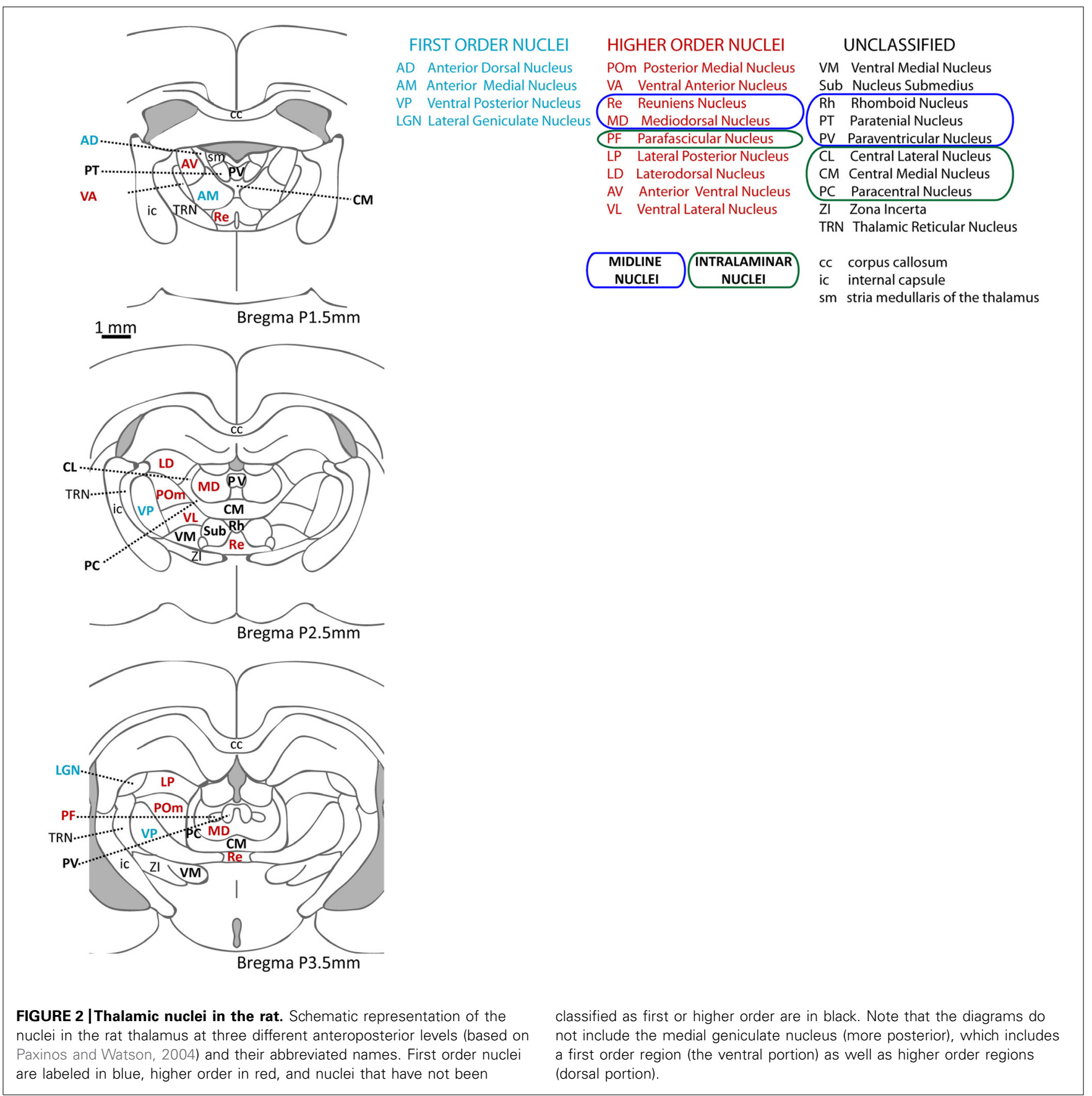


Liu et al., 1995). The location of RS contacts far from the soma is consistent with them having a weak effect on spike generation. Still, in these studies the focus was on identifying terminal types, since RS terminals are likely to correspond to modulators. When modulators are identified by their neurotransmitter (reviewed below), additional terminal types and dendritic targets can be identified. For example, some modulator terminals (e.g., some cholinergic terminals in higher order nuclei) contact proximal dendrites, overlapping with driver synapses, and can be fairly large; and yet other modulators (serotonergic, noradrenergic, histaminergic) form "en passant" synapses, with little morphological specialization.

In first order thalamus, cortical layer VI and cholinergic inputs account for the majority of modulators. Each of these inputs contributes almost $50 \%$ of the RS terminals in the cat LGN (Erisir et al., 1997b). Also, after injections of retrograde tracer in first order thalamic nuclei, and staining for the tracer and for acetylcholine markers on the brainstem, the majority of cells are double-labeled (Mesulam et al., 1983; Hallanger et al., 1987; Lee et al., 1988; Steriade et al., 1988). The proportion of retrogradely labeled cholinergic brainstem cells was in the order of $70-85 \%$ when the retrograde tracer was injected in first order nuclei like the ventral posterior, LGN, and medial geniculate (Steriade et al., 1988), suggesting that most of the brainstem modulators to these nuclei originate in cholinergic cells.

In higher order nuclei, the overall number of modulator synapses is almost twice the number in first order nuclei (Van Horn and Sherman, 2007). This difference could result from an increased number of modulator axons sent to higher order nuclei, or it could reflect an increased number of synapses per axon. It could also indicate the existence of additional afferent centers providing extra modulator input to higher order cells. Consistent with the latter, the proportion of brainstem cells projecting to higher order nuclei that were cholinergic was roughly $60 \%$ in the cat ventral anterior, ventral lateral, and anterior ventral; $45 \%$ in the macaque lateral posterior and pulvinar nuclei; and as low as $28 \%$ in the cat mediodorsal (Steriade et al., 1988), although the same study found the fraction to be $82 \%$ in the cat lateral posterior, a proportion more similar to the first order thalamus. Only 25\% of brainstem cells retrogradely labeled from tracer injections in the intralaminar centromedian and parafascicular nuclei were cholinergic (Paré et al., 1988). Overall, the evidence suggests that additional brainstem modulators (in addition to cholinergic) project to higher order nuclei.

Within the higher order nuclei, the midline and intralaminar groups are densely interconnected with executive areas (mPFC, basal ganglia). Additional higher order nuclei outside the midline and intralaminar project to executive regions (Vertes et al., 2014). For example, the anterior nuclei are highly interconnected with the cingulate and retrosplenial cortices, and with mPFC. The motor thalamus (ventral anterior, ventral lateral, and ventral medial nuclei) has projections to the basal ganglia and motor cortices. The anterior and motor groups have been studied mainly in the context of their roles in episodic memory and motor control, and little is known about their participation in executive function. For this reason, the second part of this review will focus on the midline and intralaminar nuclei.

\section{THALAMIC MODULATORS GLUTAMATE: LAYER VI CORTICOTHALAMIC MODULATORS}

Layer VI afferents are the most studied of thalamic modulators. The evidence indicates that they form a complex network from layer VI sublaminae to first and higher order thalamic nuclei; they are topographically and functionally organized, and have an important role in sensory gain control.

\section{Origin}

Thalamic glutamatergic modulators originate in layer VI of neocortical areas (Jacobson and Trojanowski, 1975; Kaitz and Robertson, 1981; Kelly and Wong, 1981; Abramson and Chalupa, 1985; Giguere and Goldman-Rakic, 1988; Conley and Raczkowski, 1990; Ojima, 1994; Bourassa et al., 1995; Bourassa and Deschênes, 1995; Lévesque and Parent, 1998; Wang et al., 1999; Murphy et al., 2000; Kakei et al., 2001; Killackey and Sherman, 2003; Cappe et al., 2007; Briggs, 2010). Allocortical areas also send afferents to the thalamus (Price and Slotnick, 1983; Cornwall and Phillipson, 1988; Groenewegen, 1988; Risold et al., 1997; McKenna and Vertes, 2004; Cenquizca and Swanson, 2006; Varela et al., 2014), although their glutamatergic nature needs confirmation. Dekker and Kuypers (1976) reported the presence of small terminals in the thalamus after injection of tritiated aminoacids in hippocampus, which suggests that they are modulators, but the driver/modulator nature of hippocampo-thalamic projections remains to be investigated with modern techniques.

In neocortex, about $30-50 \%$ of the pyramidal cells in layer VI project to the thalamus (Thomson, 2010), and the anatomy of corticothalamic projections suggests a high degree of topographic precision in the function of layer VI compared to other modulators (Murphy et al., 1999; Hazama et al., 2004). Layer VI also contains cortico-cortical projecting cells, but corticothalamic cells do not project to other cortical areas (Petrof et al., 2012). In addition, different subdivisions of layer VI project to first and higher order nuclei (Conley and Raczkowski, 1990; Bourassa et al., 1995; Bourassa and Deschênes, 1995; Killackey and Sherman, 2003), and the organization of projections increases in complexity in monkeys compared to rodents. In rats, pyramidal cells in the upper portion of layer VI of primary sensory cortices project to their corresponding first order nucleus (LGN, ventral posterior), while the lower layer VI projects to the higher order (posterior medial and lateral posterior nuclei). Axons from lower layer VI frequently branch to innervate both the first and higher order nuclei in rat (Bourassa et al., 1995; Bourassa and Deschênes, 1995). In prosimians (galago), lower layer VI cells do not branch and, instead, different subsets of cells provide input to the LGN and the pulvinar nuclei (Conley and Raczkowski, 1990). Of the three tiers of layer VI in macaques, only the upper and lower have corticothalamic projections. Each of these two sublaminae is part of a distinct functional network, with the upper layer targeting the magnocellular layers in LGN, as well as their cortical targets in layer IVCalpha. The lower layer VI sublamina projects to parvocellular LGN cells, as well as to their target, layer IVCbeta (Thomson, 2010; Briggs and Usrey, 2011). Whether functional classes in other nuclei are similarly organized in parallel circuits with layer VI remains an open question. It would be particularly interesting to investigate the functional organization in higher order cortical regions 
(mPFC, higher order sensory areas) of different animal groups, since these areas become relatively enlarged through evolution (Krubitzer and Seelke, 2012) and may gain in network complexity as well.

Higher order nuclei receive layer VI inputs from multiple cortical areas, and we know less about the specific sublaminae within layer VI that contribute afferents to higher order nuclei. One possibility is that layer VI feedback follows a similar pattern to that observed in first order. This would mean that corticothalamic afferents reciprocating a thalamocortical projection would have an upper layer VI component, whereas non-reciprocal corticothalamic projections would originate in lower layer VI. There is evidence of this arrangement in the somatosensory system, where the posterior medial nucleus receives input from upper layer VI of the non-barrel cortex to which it projects, and also from the lower layer VI of primary somatosensory cortex, a main target of the ventral posterior nucleus (Killackey and Sherman, 2003). Similar results have been reported for the macaque mediodorsal nucleus (Giguere and Goldman-Rakic, 1988), which receives upper layer VI input from $\mathrm{mPFC}$ as part of a reciprocal connection, but receives both upper and lower layer VI inputs from areas of the cingulate cortex that get only sparse mediodorsal afferents.

There is little information regarding the contributions from the contralateral hemisphere to the corticothalamic projections. Small terminals (potential layer VI projections) have been reported in the contralateral mediodorsal nucleus after unilateral tracer injections in mPFC (Négyessy et al., 1998). Contralateral projections were also demonstrated from the motor cortex to several motor, intralaminar, and somatosensory thalamic nuclei (Molinari et al., 1985; Alloway et al., 2008).

\section{Local network organization}

One of the key features that distinguish layer VI glutamatergic inputs from other glutamatergic inputs (e.g., layer $\mathrm{V}$ and noncortical drivers) is the dendritic location of their synapses. Cortical modulators target mostly distal dendrites in both first and higher order nuclei (Robson, 1983; Kultas-Ilinsky and Ilinsky, 1991; Erisir et al., 1997a; Wang et al., 1999; Bartlett et al., 2000). In fact, the glutamatergic modulators contact the relay cells in more distal locations than other modulators (Erisir et al., 1997a).

The arborization pattern of individual axons is quite distinct, and in vivo results indicate that their geometrical shape is linked to the cell's response properties. Individual axons from layer VI cells form terminal arbors with a plate-like (Ojima, 1994: ventral portion of the medial geniculate nucleus; Kakei et al., 2001: ventral anterior and lateral nuclei) or rod-like morphology (Bourassa et al., 1995: ventral posterior nucleus; Bourassa and Deschênes, 1995: LGN; Rockland, 1996: pulvinar nucleus). Bourassa et al. (1995) and Bourassa and Deschênes (1995) did not find a consistent arborization pattern in the posterior medial and lateral posterior nuclei. However, they did report that axonal plexuses were always in the horizontal plane in the lateral posterior nucleus, and showed examples of both rod and plate-like configurations. In the LGN, the orientation of the rod-like corticothalamic terminals correlates with the response properties of the cells of origin, with the orientation of the terminals being either parallel or perpendicular to the orientation preference of the cells of origin (Murphy et al., 1999); the functional correlates of these arborization patterns need to be tested in other first and in higher order nuclei.

\section{In vitro results}

Layer VI corticothalamic afferents have a direct depolarizing effect on relay cells (Scharfman etal., 1990; Reichova and Sherman, 2004; Miyata and Imoto, 2006), and an indirect hyperpolarizing effect through the activation of the thalamic reticular nucleus (TRN; Landisman and Connors, 2007; Lam and Sherman, 2010). The direct excitatory effect is mediated by both ionotropic and metabotropic receptors (mGluRs). Although with exceptions, group I mGluRs are postsynaptic, and groups II and III are localized in presynaptic terminals (Niswender and Conn, 2010). Of the two group I mGluRs, mGluR1 contributes to the corticothalamic excitatory postsynaptic potentials (EPSPs) in the LGN, ventral posterior, and posterior medial nuclei (McCormick and von Krosigk, 1992; Turner and Salt, 2000; Reichova and Sherman, 2004). Instead, groups II and III mediate presynaptic inhibition of corticothalamic responses, both the direct EPSP (Turner and Salt, 1999; Alexander and Godwin, 2005) and the inhibitory postsynaptic potentials evoked by the TRN (Salt and Turner, 1998; Turner and Salt, 2003). The inhibitory component from the TRN can also be diminished by cholinergic input (Lam and Sherman, 2010). Since activation of mGluRs increases with the intensity of stimulation, presynaptic inhibition through group II receptors could prevent over-activation or saturation of thalamic responses. Recent evidence indicates that mGluRs can also be active with relatively low frequency of stimulation, which brings up the possibility of their involvement throughout the response curve of relay cells (Viaene et al., 2013). Another property of layer VI corticothalamic synapses is that the direct response facilitates following repetitive stimulation. The facilitation is the result of both presynaptic and postsynaptic mechanisms (Miyata and Imoto, 2006; Sun and Beierlein, 2011), and it is stronger for the EPSPs evoked on relay compared to TRN cells (Alexander et al., 2006; Jurgens et al., 2012).

The activation of postsynaptic mGluRs is critical for one the proposed functions of corticothalamic modulators: switching the firing mode of relay cells (McCormick and von Krosigk, 1992; Godwin et al., 1996). Relay cells in the thalamus fire spikes in two modes, burst and tonic (Jahnsen and Llinás, 1984). In tonic mode, relay cells respond in a linear fashion to their inputs, while burst firing is non-linear but provides better detectability (Sherman, 2001). Burst firing relies on the activation of a transient (T-type), low threshold, calcium current. Changes in membrane potential determine the de-inactivation and activation state of the calcium channels responsible for burst firing (Jahnsen and Llinás, 1984; Gutierrez et al., 2001). De-inactivation of the T current takes about $100 \mathrm{~ms}$, which falls within the timeframe of mGluRs responses. The relatively slow dynamics of mGluRs leads to slow changes in the membrane potential that can influence the firing mode. Thus, layer VI activation of a relay cell would make it more likely to fire spikes in tonic mode, facilitating faithful signal transmission (Sherman, 2001).

\section{Systems level}

Most of the in vivo studies on corticothalamic projections have been done in the visual system in anesthetized preparations 
(recent reviews include Cudeiro and Sillito, 2006; Sillito et al., 2006; Briggs and Usrey, 2011), and only recently in awake animals (Olsen et al., 2012; Pais-Vieira et al., 2013). In the visual system, layer VI corticothalamic projections can influence centersurround strength without changing the spatial selectivity of receptive fields (Rivadulla et al., 2002; Jones et al., 2012). An important aspect of the corticothalamic input is that it is topographically and functionally organized, meaning that specific functional types of LGN cells (X, Y, W or parvocellular, magnocellular, koniocellular) will be influenced by layer VI cells with similar response properties. However, the effect on the firing rate of relay cells is reversed depending on the overlap of on-off receptive field regions. For example, an on-center relay cell with a receptive field overlapping with the "off" portion of a corticothalamic receptive field, would receive an excitatory influence from cortex, whereas if the overlapping fields were of the same sign, the influence would be inhibitory (Wang et al., 2006). Topographically organized effects are also observed in the somatosensory system, where activation of layer VI cells produced opposite effects on simultaneously recorded neighboring thalamic barreloids. During layer VI activation, cells in non-aligned thalamic barreloids were suppressed and less selective to preferred whisker stimulation. Instead, during activation of layer VI, responses in the topographically aligned barreloid were selectively increased to preferred whisker stimulation, leading to an increase in spatial tuning selectivity (Temereanca and Simons, 2004). Enhanced responses were also seen in thalamic barreloids after activation of topographically aligned regions in motor cortex, which could contribute to sensory gating and anticipatory responses in cortex and thalamus during active whisking (Lee et al., 2008; Pais-Vieira et al., 2013).

The results from sensory systems demonstrate contributions to sensory processing, but corticothalamic inputs are found in every thalamic nucleus, which implies functions beyond specific sensory modalities. Layer VI cells receive input from all cortical layers and could serve to integrate processed cortical information with the direct input from the thalamus (Thomson, 2010). On the other hand, the effect of corticothalamic inputs on membrane potential points to a gain control system. There is evidence in support of the gain control hypothesis in the mouse visual cortex (Olsen et al., 2012), in which optogenetic manipulation (activation and inhibition) of layer VI scaled the tuning curves of cortical cells up and down without changes in response selectivity (Figure 3). Stimulation of layer VI linearly reduced cortical responses to the presentation of full-field gratings moving in different directions (Figures 3A-C), while inhibition of layer VI increased cortical responses (Figures 3D-F). This linear modification of the cortical tuning curves was found to result from the effect of layer VI on other cortical layers and on thalamic LGN cells. However, the effect on tuning curves was not tested in LGN, and the role of layer VI on gain control deserves further exploration at the thalamic level. In particular, although other modulators have an effect on membrane potential and could influence thalamic gain, the topographic and functional organization of the corticothalamic projection suggests that layer VI provides a more precise control than other modulators. Along these lines, corticothalamic projections could carry out topographically specific, top-down gain control in sensory nuclei as

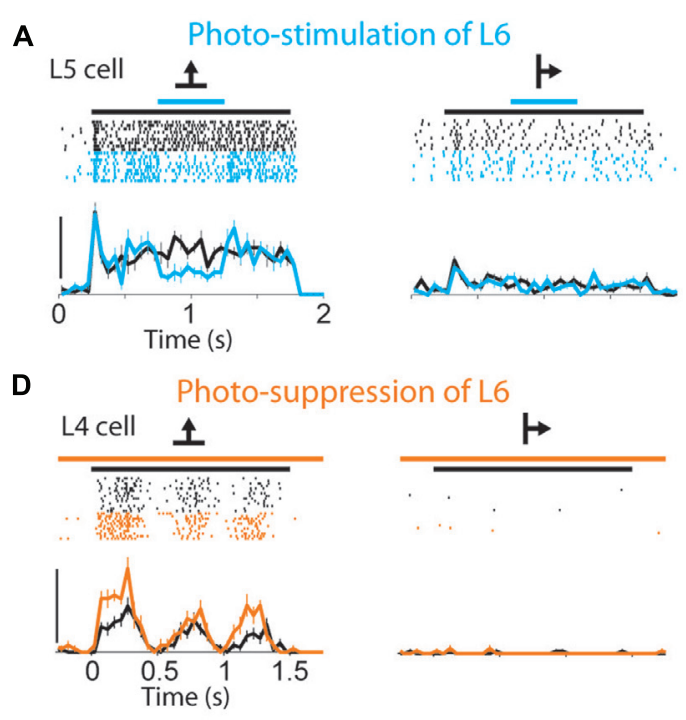

FIGURE 3 | Layer VI contributes to gain control in mouse visual cortex. (A) Response of a layer $V$ cell (spike rasters and peri-stimulus histograms) to visual stimuli with and without photostimulation of layer VI; black line above raster indicates stimulus presentation, blue indicates the time of optogenetic activation of layer VI. Visual stimuli were full-field gratings drifting in different directions (arrows); scale bar, 40 spikes/s. (B) Tuning curves for the cell in (A), including the responses to nine stimulus directions, with (blue) and without (black) photostimulation of layer VI. (C) Population tuning curve with (blue) and
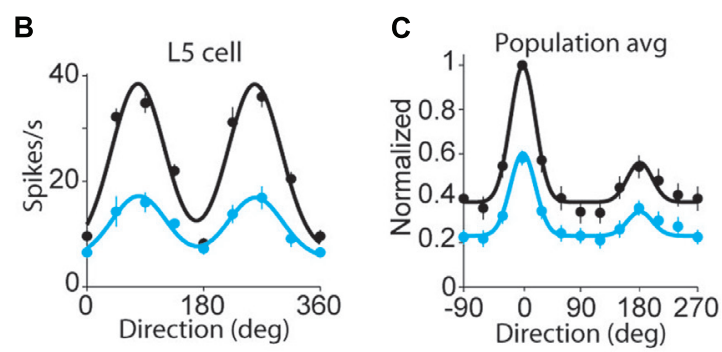

E

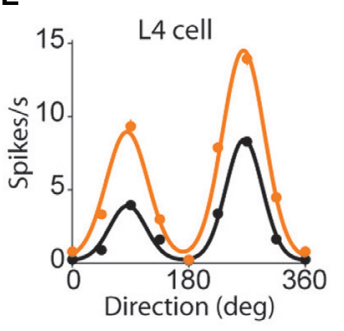

$\mathbf{F}$

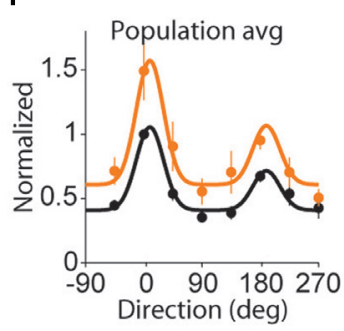

without (black) photostimulation of layer VI; the population tuning curve was generated by first circularly shifting the stimulus direction for each unit so that the maximal response occurred at $0^{\circ}$. The responses were then normalized to this peak response and averaged ( $n=55$ units). (D-F) same as (A-C) but during photosuppression of layer $\mathrm{VI}$, and using a cell from layer IV as example; scale bar in (D) 50 spikes/s; population tuning curve in (F) is the average of $n=52$ units. (Reprinted from Olsen et al., 2012, with permission from Macmillan Publishers.) 
a function of ongoing neocortical processing. It has also been suggested that they could implement predictive modulation (Sillito et al., 2006) in expectation of stimulus arrival or stimulus changes, such as when processing a moving stimulus. Future experiments should test these hypotheses, and step beyond sensory cortices to explore the role of layer VI in other thalamocortical networks.

\section{ACETYLCHOLINE}

Cholinergic systems have been broadly involved in state regulation (sleep-wake cycle, attention) and may contribute to state dependent changes in information routing in neocortex. The thalamus receives cholinergic input from a variety of sources that preferentially innervate higher order nuclei and, through these nuclei, could contribute to cholinergic mediated modulation in neocortex. In the thalamus, cholinergic terminals can have large synaptic boutons (with potentially strong postsynaptic effects), and the effect on relay cells can be circuit specific, determined by the cell's projection target.

\section{Origin}

Cholinergic input to the thalamus originates mainly in the pedunculopontine (PPT) and the laterodorsal tegmental (LDT) nuclei (Saper and Loewy, 1980; Mesulam et al., 1983; Sofroniew et al., 1985; Woolf and Butcher, 1986). Cholinergic neurons in the PPT and LDT are intermingled with non-cholinergic neurons but, after injection of retrograde tracers in the thalamus, most of the retrograde tracer is found in choline acetyltransferase positive neurons, suggesting that the non-cholinergic cells project sparsely to the thalamus (Mesulam et al., 1983; Sofroniew et al., 1985). Besides the PPT and LDT afferents, some thalamic nuclei (the mediodorsal, anterior ventral, anterior medial, and anterior intralaminar nuclei) receive cholinergic projections from the basal forebrain (Hallanger et al., 1987; Parent et al., 1988; Steriade etal., 1988; Heckers etal., 1992; Gritti et al., 1998), a region otherwise projecting to cortical areas and to the TRN (Saper, 1984; Hallanger et al., 1987). The parabigeminal nuclei provide additional cholinergic input to the LGN of cats and monkeys, a projection that is both ipsi- and contralateral in cats and strictly contralateral in the tree shrew (De Lima and Singer, 1987; Fitzpatrick etal., 1988, 1989; Smith et al., 1988; Bickford et al., 2000). Lastly, cholinergic neurons from the entopeduncular nucleus (Kha et al., 2000) and substantia nigra (pars reticulata; Kha etal., 2001) send axons to the rat ventral lateral and ventral medial nuclei, both part of the motor thalamus. Within the diencephalon, the medial habenula contains cholinergic neurons (Levey etal., 1987; Heckers etal., 1992), but its efferents appear to be directed outside the dorsal thalamus (Vincent et al., 1980).

\section{Local network organization}

PPT and LDT cholinergic projections have preferential targets within the thalamus. Sensory nuclei (LGN, ventral posterior, and the medial geniculate nuclei) receive most of their cholinergic afferents from PPT, whereas higher order nuclei and the anterior group have a LDT component (Woolf and Butcher, 1986; Hallanger et al., 1987; Smith et al., 1988; Steriade et al., 1988). This additional LDT innervation may contribute to the higher density of cholinergic fibers observed in some higher order compared to first order nuclei (Parent and Descarries, 2008).

Within the higher order group, the mediodorsal, the lateral posterior, ventral anterior, ventral lateral, laterodorsal, and posterior nuclei receive a substantial fraction of their cholinergic input from LDT. The two latter nuclei receive about two thirds of their brainstem cholinergic input from PPT and a third from LDT. Within the intralaminar, the central lateral seems to be primarily targeted by PPT, while the central medial has a large component from LDT (Woolf and Butcher, 1986; Hallanger et al., 1987). Anterograde tracers have also demonstrated LDT projections to the midline nuclei (Kuroda and Price, 1991); however, the relative contribution of PPT and LDT to the midline cholinergic innervation was not addressed in this study.

At least some of the cholinergic brainstem axons have collaterals that innervate more than one nucleus in the dorsal thalamus (Uhlrich et al., 1988; Shiromani et al., 1990; Bolton et al., 1993), and can innervate the TRN as well (Spreafico et al., 1993). In some cases, the axons remain within nuclei of a particular sensory modality; e.g., the collaterals that innervate the LGN, lateral posterior, and pulvinar nuclei in cat (Uhlrich et al., 1988). There are other patterns of collateral projections, e.g., those that branch into several of the midline nuclei, or to midline and intralaminar (Bolton et al., 1993), or to LGN and intralaminar nuclei (Shiromani et al., 1990). More localized projections have been documented in the visual thalamus. Here, some axons terminate only in the LGN or only in the lateral posterior and pulvinar nuclei. Axons within the LGN distribute terminals across laminae or inside individual laminae (Uhlrich et al., 1988). It should be noted that in this study axons were not identified as cholinergic; however, results from retrograde tracer studies (see introduction) suggest that most or all of the reconstructed axons were cholinergic.

Cholinergic cells projecting to the thalamus can have branches to extra-thalamic regions as well. PPT projects both to the LGN and to the superior colliculus (Billet et al., 1999). Similarly, subsets of cells in PPT and LDT that project to the thalamus also project to the pontine reticular formation (Semba et al., 1990) and to the basal forebrain (Losier and Semba, 1993). The collaterals of cholinergic projections may contribute to the multi-regional coordination of state changes brought about by this system.

The ultrastructure of cholinergic terminals has been studied in a few first order - LGN, ventral posterior -, and higher order anterior ventral, mediodorsal, parafascicular - nuclei (Hallanger et al., 1990; Kuroda and Price, 1991; Parent and Descarries, 2008). One feature of the LGN PPT terminals is that they contain the enzyme nitric oxide synthase (Cucchiaro et al., 1988; Hallanger et al., 1990; Bickford et al., 1993; Erisir et al., 1997a). In fact, cholinergic afferents may be the main, or even the sole, source of nitric oxide in the thalamus; although some serotonergic cells in the raphe express nitric oxide synthase, they do not project to the thalamus (Simpson et al., 2003). In the LGN, PPT terminals form asymmetric synapses on proximal and distal dendrites of relay cells, often in the vicinity of driver synapses, and occasionally in the soma. Compared to the LGN, the cholinergic terminals in the ventral posterior nucleus are sparser, smaller, and they 
establish asymmetric synapses on small dendrites (farther from the soma; Hallanger et al., 1990). The main difference between the ultrastructure of cholinergic terminals in first order and higher order nuclei is the much larger size in higher order. In both the mediodorsal and parafascicular nuclei, they can reach more than $2 \mu \mathrm{m}$ (Hallanger et al., 1990; Kuroda and Price, 1991). In the mediodorsal nucleus, $90 \%$ of LDT boutons were larger than $1 \mu \mathrm{m}$, which is a size range more typical of drivers. In the ventral anterior nucleus, cholinergic terminals were less than $1 \mu \mathrm{m}$, but still larger on average than the terminals reported in the LGN and ventral posterior nuclei in the same preparation, suggesting a stronger effect on cells of higher order nuclei. The cholinergic terminals in the anterior ventral nucleus contacted dendrites of various sizes (often small dendrites and rarely somas), and they made occasional symmetric synapses in addition to the most common asymmetric contacts (Hallanger et al., 1990). The presence of nitric oxide synthase was not tested in higher order nuclei.

The larger cholinergic terminal size and fiber density in higher order nuclei may result in stronger postsynaptic effects on higher order compared to first order relay cells, something that can have important implications in cortical regions. As an example, association neocortical areas (those receiving afferents from higher order nuclei) present greater attentional modulation than primary cortical regions (Bender and Youakim, 2001; Maunsell and Cook, 2002), a function in which the cholinergic system may be involved. The attentional modulation observed in neocortex could reflect modulation at the thalamic level. Indeed, the evidence suggests that higher order nuclei, such as the pulvinar nucleus, have stronger attentional modulation than first order like the LGN (Bender and Youakim, 2001), and contribute to corticocortical synchronization during attentional tasks (Saalmann et al., 2012). Future manipulation experiments of higher order nuclei while observing the effect on attentional modulation in thalamus and cortex simultaneously, will help clarify the causal contribution of the thalamus to attentional modulation in cortical regions.

Another open question is the origin of the large cholinergic terminals. Higher order nuclei receive a substantial projection from the LDT, and one possibility is that LDT axons provide the larger terminals observed in the thalamus. A further point related to the terminal size is that large terminal size is commonly associated with drivers and not modulators. Cholinergic afferents with large terminals could have a strong effect on spike generation probability on higher order cells (e.g., in the mediodorsal and parafascicular nuclei) because, in addition to having a large size, cholinergic terminals in these cells contact dendritic regions that are close to the soma. Both the lateral mediodorsal nucleus and LDT have been suggested to participate in oculomotor control (Kuroda and Price, 1991 ) and it is possible that the LDT projection represents a driver input to the mediodorsal nucleus.

\section{In vitro and systems level}

Cholinergic activation depolarizes the majority of thalamic cells (Sillito etal., 1983; Francesconi et al., 1988; Curró Dossi etal., 1991), although some relay cells, as well as thalamic interneurons, are hyperpolarized by cholinergic agonists (McCormick and
Prince, 1986; McCormick and Pape, 1988; Hu et al., 1989; Murphy et al., 1994; Zhu and Heggelund, 2001; Varela and Sherman, 2007). In general, relay cells that are hyperpolarized by acetylcholine are in higher order nuclei (MacLeod et al., 1984; Mooney et al., 2004; Varela and Sherman, 2007; Beatty et al., 2009). Interestingly, at least in one higher order nucleus (the parafascicular), the sign of the cholinergic effect correlates with the projection target of the cell. Relay cells projecting to neocortex are depolarized by cholinergic agonists, whereas those projecting to striatum are inhibited (Beatty et al., 2009). This result has key implications for the function of thalamostriatal projections in behavioral flexibility, and will be discussed in the second part of this review. It also raises the possibility that the depolarizing or hyperpolarizing effect of modulators may be pathway specific in other nuclei; given the variety of modulator effects in higher order nuclei (Figure 4), the correlation between modulator effect and projection target needs to be tested for pathways from these nuclei.

Mixed responses, in which a hyperpolarization is followed by depolarization, have also been reported. This combined response was observed in the lateral posterior nucleus, in interneurons of the LGN (Zhu and Heggelund, 2001), and in a subset of cells of the ventral medial nucleus (MacLeod et al., 1984). It was also reported in about half of the cells in the guinea pig lateral and medial geniculate nuclei (McCormick and Prince, 1987; McCormick, 1992), and could represent species differences, with depolarization being the most common response in rat first order nuclei.

Overall, cholinergic-evoked depolarization (whether by itself or as part of a mixed response) is mediated by ionotropic and muscarinic (M1, M3) receptors (Zhu and Uhlrich, 1997, 1998; Mooney et al., 2004; Varela and Sherman, 2007), whereas the M2 muscarinic receptor is responsible for the hyperpolarization of GABAergic cells (McCormick and Prince, 1986; Zhu and Heggelund, 2001).

Aside from the effect on membrane potential, other effects of acetylcholine at the thalamic level have not been extensively studied. Results outside the thalamus suggest that there is much to be explored regarding the functions of the cholinergic system in the thalamus (Picciotto et al., 2012), especially in behaving animals. In the slice preparation, acetylcholine affects neurotransmitter release and synaptic strength in intracortical and thalamocortical synapses (Favero et al., 2012), changes that can be important during the implementation of bottomup and top-down attentional regulation (Varela, 2013) and can only be studied in the behaving animal. In addition, results from a head-restrained preparation show that the effects on membrane potential observed in the slice may vary in vivo throughout the sleep-wake cycle. Iontophoretic application of cholinergic agonists in the LGN depolarized cells during wakefulness, as expected from the in vitro results, but had heterogeneous effects during slow-wave sleep (Marks and Roffwarg, 1989). Lastly, cholinergic activation enhances thalamocortical information transmission through nicotinic receptors located along the axons of the thalamocortical pathway (Kawai et al., 2007), a result that remains to be investigated in thalamic projections to other targets, like the basal ganglia and hippocampus. 


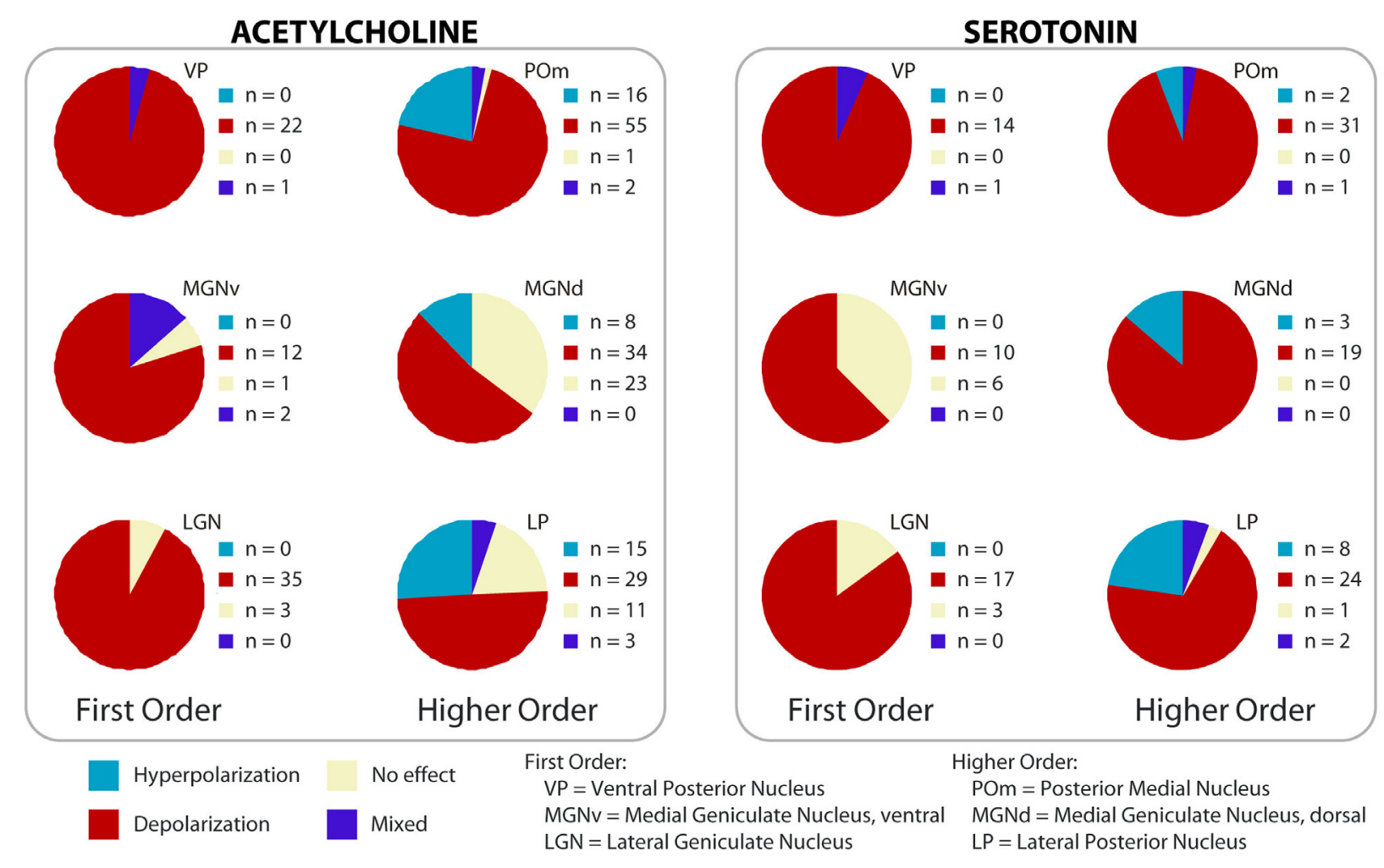

FIGURE 4 | Effect of cholinergic and serotonergic agonists on first and higher order nuclei. Summary of the effects on membrane potential across thalamic nuclei from whole-cell patch clamp experiments in rat slices; data are color-coded according to the overall effect on excitability.
Hyperpolarization was only found in higher order nuclei. First order nuclei tested: VP, MGNv, LGN; higher order tested: POm, MGNd, LP. (Modified from Varela and Sherman, 2007, 2009; with permission from the American Physiological Society and from Oxford University Press.)

\section{SEROTONIN}

Serotonergic afferents to the thalamus have not received much attention, in spite of the critical involvement of serotonin in the control of the sleep-wake cycle and in disorders like depression (Monti, 2011; Kupfer et al., 2012). In the thalamus, serotonergic afferents target preferentially higher order nuclei, where they have heterogeneous effects on membrane potential and could evoke changes in firing mode throughout the sleep-wake cycle.

\section{Origin and local network organization}

The serotonergic axons innervating the thalamus have their origin in the medial and lateral divisions of the dorsal raphe (De Lima and Singer, 1987; Vertes, 1991; Gonzalo-Ruiz et al., 1995; Vertes et al., 1999, 2010; Kirifides et al., 2001), and in the median raphe (Gonzalo-Ruiz et al., 1995; Vertes et al., 1999). The projections do not always overlap; for example, the median raphe projects most heavily to the lateral mediodorsal nucleus, while the medial mediodorsal nucleus receives serotonergic input from the dorsal raphe (Groenewegen, 1988).

Just like with the cholinergic input, the distribution of serotonergic fibers within the thalamus is not uniform. The preferential targets are the midline and intralaminar nuclei, and, more generally, the higher order nuclei. The rest of the dorsal thalamus receives sparse innervation with the exception of the LGN (Cropper et al., 1984; Lavoie and Parent, 1991; Vertes, 1991; Vertes et al., 1999, 2010). There is some evidence of local differences in innervation density within nuclei. The heaviest serotonergic innervation in the LGN is generally found in structures receiving input from W-ganglion cells (Ueda and Sano, 1986; Mize and Payne, 1987; Fitzpatrick et al., 1989), although others have found uniform innervation across the LGN and lateral posterior and pulvinar nuclei (Morrison and Foote, 1986).

Serotonergic afferents form asymmetric synapses along the dendrites (distal and proximal) of thalamic cells (Pasik et al., 1988; Liu and Jones, 1991). They also form atypical contacts (Liu and Jones, 1991), meaning that they do not present all the morphological specializations of a synapse, only a close membrane apposition.

\section{In vitro and systems level}

Serotonin depolarizes thalamic cells in first order nuclei, such as the LGN, the ventral portion of the medial geniculate, the ventral posterior, and the anterior dorsal nuclei (Pape and McCormick, 1989; McCormick and Pape, 1990; Chapin and Andrade, 2001a; Monckton and McCormick, 2002). The depolarization results, at least in part, from changes in the voltage-dependence of the hyperpolarization-activated current, $\mathrm{I}_{\mathrm{h}}$ (Pape and McCormick, 1989; McCormick and Pape, 1990; Chapin and Andrade, 2001b; Monckton and McCormick, 2002). Subsets of cells in higher order nuclei are either depolarized or hyperpolarized, and the 
proportion of cells that show one or the other response varies between species (Monckton and McCormick, 2002; Varela and Sherman, 2009). When compared in the same preparation, the depolarization is much stronger in higher order than in first order areas (Varela and Sherman, 2009), consistent with the denser innervation in those nuclei. Overall, both acetylcholine and serotonin inhibit a subset of cells specifically in higher order nuclei, while the effect is mostly depolarizing in first order (Figure 4). The inhibition of cells in higher order means that, when active, these modulators could switch some cells to burst mode, which can contribute to the finding of more bursting in higher compared to first order nuclei (Ramcharan et al., 2005). In addition to the effect on the membrane potential, there is evidence that serotonin affects the response properties of some relay cells. Cells in the midline and intralaminar nuclei have a strong slow afterhyperpolarization (sAHP) that can last several seconds after a train of spikes. Serotonin depolarizes cells in these nuclei and inhibits the sAHP through 5-HT-7 receptors (Goaillard and Vincent, 2002).

There is little information from in vivo preparations on the role of serotonin on thalamic function. Activation of the dorsal raphe nucleus was reported to inhibit LGN cells in the anesthetized preparation (Kayama etal., 1989). However, this was observed after several seconds of stimulation, and could result from changes in synaptic plasticity somewhere else in the brain (Lesch and Waider, 2012). Another report in the anesthetized preparation (Grasso et al., 2006), found that serotonergic agonists infused in the motor thalamus (ventral anterior and ventral lateral nuclei) produced an inhibition of the discharge of these cells, consistent with the in vitro findings in higher order nuclei. The systems level approach to serotonergic function in the thalamus remains essentially uninvestigated. The study of serotonin outside the thalamus hints at critical roles for this neurotransmitter; from synapse development and plasticity to the learning of fear responses (Lesch and Waider, 2012). Future experiments should characterize the effect of serotonergic afferents on sensory responses, and on the response mode of thalamic cells across sleep states. Much like brainstem cholinergic centers, cells in the raphe change their activity as a function of state (Monti, 2011). Many of the raphe cells are REMOFF, suggesting a reduction in serotonergic tone in the thalamus during REM, a reduction that can selectively affect the firing mode of higher order cells. An intriguing idea is that changes in firing mode in higher order nuclei could contribute to the selective activation of higher order cortical areas during REM, an activation that is thought to underlie dreaming (Hobson et al., 1998).

\section{NORADRENALINE}

Like with serotonin, the studies of noradrenergic modulation in the thalamus are fairly limited and much remains to be investigated. Recent evidence offers important cues that could instigate further research on this neurotransmitter; these results suggest a role of thalamic noradrenaline in sensory gating and in certain motor and executive disorders.

\section{Origin and local network organization}

The cells that provide noradrenergic afferents to the brain are located in the locus coeruleus (LC) and in the brainstem reticular formation. The thalamus receives its noradrenergic input mostly from cells in the LC-many of which also contain galanin (Simpson et al., 1997). Additional projections have been reported for the midline paraventricular nucleus from the A5 noradrenergic region in the brainstem (Swanson and Hartman, 1975; Morrison and Foote, 1986; Byrum and Guyenet, 1987; De Lima and Singer, 1987; Simpson et al., 1997; Vogt et al., 2008).

As with acetylcholine and serotonin, there are regional differences in the innervation of thalamic nuclei. For example, the LGN is virtually free of noradrenergic fibers, while the lateral posterior and pulvinar nuclei are densely innervated (Morrison and Foote, 1986). In the somatosensory thalamus, noradrenergic innervation is denser in the posterior medial nucleus (higher order) compared to the ventral posterior nucleus (Simpson et al., 1999). Therefore, similar to other modulators, the results in the sensory thalamus point to a more prominent role of noradrenaline in higher compared to first order nuclei. However, the limited evidence from the midline and intralaminar nuclei suggests that they receive sparse noradrenergic innervation, except for the midline paraventricular nucleus (Swanson and Hartman, 1975). Regarding ultrastructure, noradrenergic terminals in the thalamus are small, and, like serotonergic terminals, do not seem to form well differentiated synapses (Nothias et al., 1988).

\section{In vitro and systems level}

Noradrenaline applied in vitro to the LGN, medial geniculate, TRN, anterior ventral, and the paratenial nuclei, evoked a slow depolarization, which in turn reduced burst firing and promoted tonic activity (McCormick and Prince, 1988). The authors found that the depolarization was caused by a decrease in a potassium leak current and by changes in the voltage sensitivity of the $\mathrm{I}_{\mathrm{h}}$ current. The $I_{h}$ current could then remain active at resting membrane potentials and make it more difficult for cells to switch to burst mode (Pape and McCormick, 1989; McCormick and Pape, 1990). The effect of noradrenaline on the response properties of relay cells was tested in paratenial neurons, in which noradrenaline reduced the sAHP and decreased spike frequency adaptation (McCormick and Prince, 1988).

In vivo, in the anesthetized preparation, iontophoretic application of noradrenergic agonists inhibits thalamic cells in the motor thalamus (ventral anterior and ventral medial nuclei; Grasso et al., 2006). The sign of the effect is the opposite of that found by in vitro experiments, where depolarization was common. More research is needed to clarify if the different results indicate the variability of the responses across thalamic nuclei, or an effect of the anesthesia. Evidence from the awake preparation suggests that, although depolarization predominates in the somatosensory thalamus, inhibitory responses are fairly common too. Responses to whisker stimulation increased in most cells of the ventral posterior nucleus during stimulation of the LC, although between 20\% (Moxon et al., 2007) and almost 40\% (Devilbiss and Waterhouse, 2011) of the cells showed a suppression of their response. In particular, phasic stimulation of the LC had a permissive or "gating" effect in some cells, facilitating the response to a stimulus that the cell would otherwise not respond to in the absence of LC stimulation. Stimulation of the LC also enhanced the synchronization of sensory responses 
between simultaneously recorded cells in the ventral posterior nucleus, with potential implications on temporal summation at the cortical level (Devilbiss and Waterhouse, 2011). Furthermore, noradrenaline changed the synaptic strength of intracortical and thalamocortical synapses in the slice preparation (Favero et al., 2012). In this study, noradrenaline facilitated thalamocortical relative to intracortical transmission in the input layers of cortex, a result that has implications for the routing of external vs. internal information during the sleep-wake cycle (Varela, 2013).

Aside from the effects on sensory gating, recent evidence suggests the involvement of thalamic noradrenaline modulation in executive and motor disorders. Infusion of noradrenergic agonists (but not serotonin) in the mediodorsal nucleus disrupts prepulse inhibition; prepulse inhibition paradigms are used as indicators of sensorimotor gating disruption in neuropsychiatric disorders, and it was suggested that noradrenergic activation in the mediodorsal nucleus reproduces some of the sensorimotor gating deficits observed in these disorders (Alsene et al., 2011). Likewise, noradrenaline may be critical for the normal function of the motor thalamus, which is suggested by the specific decrease of this neurotransmitter in the motor thalamus of the symptomatic MPTP (methyl-phenyl-tetrahydropyridine) primate model of Parkinson disease (Pifl et al., 2013). Overall, the available evidence indicates that noradrenergic modulation in the thalamus can influence sensory responses and, potentially, has considerable clinical relevance.

\section{DOPAMINE}

Dopamine is one of the thalamic modulators with more direct involvement in disease. The degeneration of dopaminergic cells in the substantia nigra pars compacta links this modulator to the pathogenesis of Parkinson disease. In addition, the role of dopaminergic cells from the ventral tegmental area (VTA) in reward signaling is thought to contribute to addiction, and to the symptomatology of disorders such as schizophrenia and depression. The thalamus does not receive strong dopaminergic innervation from the substantia nigra, but it gets dopamine afferents from the VTA and additional mesencephalic and diencephalic regions. Also, dopaminergic terminals are often near thalamic terminals at their targets (e.g., neocortex, striatum), indicating that at least some of the thalamic dopaminergic modulation may occur not at the soma, but at the terminal site.

\section{Origin and local network organization}

There is a wide range of brain areas, particularly in the primate, that provide dopaminergic input to the thalamus, including the hypothalamus, zona incerta, the VTA, the periaqueductal gray, and the lateral parabrachial nucleus, all of which project bilaterally to most nuclei of the macaque thalamus (Hughes and Mullikin, 1984; Sánchez-González et al., 2005). Dopaminergic projections to the thalamus from the substantia nigra are minimal, although there are non-dopaminergic projections from this region (Kuroda and Price, 1991; Sánchez-González et al., 2005; Melchitzky etal., 2006; Kusnoor etal., 2012). Some afferents, like those from the VTA, project broadly across the thalamus, whereas others have restricted projections, like those from the hypothalamus and zona incerta, which have dense projections to the midline thalamus. Most of the projections to the midline do not express the dopamine transporter, and it has been suggested that the absence of the transporter could make the effect of dopamine less time and spatially restricted in these nuclei. The absence of the dopamine transporter has clinical implications as well, because this transporter is the point of action of drugs (amphetamines) and toxins (MPTP), suggesting that the midline dopaminergic afferents would be relatively protected against these substances compared to other nuclei (Sánchez-González et al., 2005).

There are important species differences in the density of thalamic dopaminergic innervation, with the primate thalamus having substantially higher densities compared to the rat (García-Cabezas et al., 2009). Dopaminergic fibers in the thalamus of primates often display higher densities than in cortex, and the density is highest in the motor and midline thalamus, and the lateral posterior nucleus (Sánchez-González et al., 2005); the lowest densities are found in sensory first order nuclei (LGN, medial geniculate, and ventral posterior nuclei). In primates, dopaminergic terminals contact the presynaptic dendrites of thalamic interneurons, raising the possibility that the denser dopaminergic innervation in primates is related to the increased number of interneurons in these animals (García-Cabezas et al., 2009).

\section{In vitro and systems level}

Outside of the thalamus, two types of dopaminergic receptors, D1 and D2, are often segregated in functional circuits, something that has yet to be explored in detail in the thalamus. Along these lines, D2 receptors are highly expressed in midline and intralaminar nuclei (Rieck et al., 2004; Piggott et al., 2007), and D1-D2 receptors mediate different effects on membrane potential in different nuclei. D1 mediates the depolarization of rat LGN cells in slices (Govindaiah and Cox, 2005), and D2 the hyperpolarization of most cells in the mediodorsal nucleus (Lavin and Grace, 1998). Furthermore, in the mediodorsal nucleus, D2 can influence the cells response properties, by facilitating the occurrence of low threshold burst spikes and increasing the sAHP (Lavin and Grace, 1998). Other dopaminergic receptors are present in the presynaptic terminals of thalamic afferents; for example, D4 can presynaptically and selectively decrease the inhibitory input from the globus pallidus to the TRN (Govindaiah et al., 2010).

In vivo, the results of iontophoretic application of dopamine were found to be dose-dependent, with dopamine facilitating visual responses at low doses and inhibiting responses at higher doses (Albrecht et al., 1996; Zhao et al., 2001, 2002). The inhibition at higher doses could result from the activation of local interneurons or TRN cells. Iontophoresis of D1 agonists suppressed visual responses in these studies, something in contrast to the depolarization seen in slices (Govindaiah and Cox, 2005); the use of more selective agonists and antagonists could help resolve the differences and characterize the effect of dopamine in sensory evoked responses.

The relatively weak dopaminergic innervation of the rat thalamus may have discouraged research on the function of this modulator at the thalamic level. However, the importance of dopamine 
modulation on thalamic function should not be underestimated. First, the dramatic increase in dopaminergic innervation in the primate thalamus compared to the rodent thalamus points to the evolutionary relevance of this system; it also suggests that dopamine may be specifically relevant for those functions that gain in importance through evolution, such as higher order cognitive functions. And, second, dopaminergic and thalamic synapses often converge on the same postsynaptic targets outside of the thalamus (Kuroda et al., 1996), suggesting that thalamic dopaminergic modulation may be more likely to occur at the level of thalamic terminals than at the soma.

\section{HISTAMINE}

Very little is known about the modulator functions of histamine in the thalamus, with most of the evidence coming from studies in the LGN. The activity of histaminergic cells varies across the sleep-wake cycle suggesting that, similar to serotonin, noradrenaline, and acetylcholine, this modulator may be involved in the regulation of general changes of activity across states of vigilance. However, the effect of histamine on the excitability of thalamic cells, and the selective modulation of thalamostriatal terminals by histamine suggest more complex functions that need to be investigated.

\section{Origin and local network organization}

Histaminergic input arises from the tuberomammillary nucleus of the hypothalamus (Manning et al., 1996; Blandina et al., 2012). In the cat LGN, histaminergic fibers have a preference for zones innervated by the W-cell system (Uhlrich et al., 1993), although their distribution is more homogeneous in the macaque LGN (Manning et al., 1996; Wilson et al., 1999). No clear synaptic contacts were observed, only en passant swellings, which hint to a diffuse modulation mechanism (Uhlrich et al., 1993; Wilson et al., 1999).

\section{In vitro and systems level}

In vitro, LGN cells are depolarized by histamine. The response has two components, the main one being an increase in input resistance mediated by $\mathrm{H} 1$ receptors. The second component is a smaller depolarization, which is observed after blockade of $\mathrm{H} 1$ receptors, is mediated by $\mathrm{H} 2$ receptors, and is associated with a decrease in input resistance (McCormick and Williamson, 1991). These in vitro results in the LGN are consistent with the effect of activating the tuberomammillary region in vivo, which results in increased firing in LGN cells, with no change of their spatial frequency tuning (Uhlrich et al., 2002). Conversely, a study testing iontophoretically applied histamine in the anterior and intralaminar nuclei found an inhibition of baseline firing (Sittig and Davidowa, 2001). More research is needed to characterize the effects of histamine across the thalamus and identify the receptors that mediate the responses in different nuclei. There are additional histaminergic receptors in thalamic cells $(\mathrm{H} 3, \mathrm{H} 4)$, but evidence of their function is limited (Strakhova et al., 2009). In particular, $\mathrm{H} 3$ presynaptic receptors could be important in the modulation of thalamostriatal terminals, where they are expressed; these receptors selectively facilitate thalamostriatal - and not corticostriatal - synapses during repetitive stimulation (Ellender et al., 2011).
Cells of the tuberomammilary nucleus are only active during wakefulness and their degree of activation correlates with alertness levels (Takahashi et al., 2006), suggesting that its function in the thalamus may relate to attentional levels and state related changes through the sleep-wake cycle.

\section{THALAMIC MODULATORS AND EXECUTIVE FUNCTION}

The data reviewed in the previous section suggests that modulators contribute to the function of virtually all thalamic nuclei and may be critical in higher order nuclei. These nuclei receive a higher proportion of modulators than first order, have cell populations with heterogeneous responses to modulators, and are interconnected with brain regions that are themselves under strong modulator control.

One feature that characterizes higher order thalamic nuclei is the complexity of their projections. Whereas sensory nuclei have relatively confined projection targets within neocortex, higher order nuclei project to multiple regions within and outside of neocortex. Targets include the basal ganglia, hippocampus, hypothalamus, and amygdala. Among them, mPFC and the striatum have been identified as key structures in the control of executive function. Although a few other thalamic nuclei project to these two areas, the following section will focus on the modulation of two groups of nuclei that have strong connections with $\mathrm{mPFC}$ and the striatum: the midline and the intralaminar groups (Hoover and Vertes, 2007; Galvan and Smith, 2011). The midline group includes, ventrally, the reuniens and rhomboid nuclei, and, more dorsally, the paratenial, paraventricular, and mediodorsal nuclei. This group is defined primarily by its position along the midline of the thalamus, and the mediodorsal, the reuniens, and the paratenial nuclei also originate from the same pronuclear mass during development (Jones, 2007). The intralaminar nuclei follow an anteroposterior axis, with the rostral part including the central lateral, paracentral, and central medial nuclei. The parafascicular nucleus, together with the centromedian nucleus in primates, constitute the caudal components of the intralaminar group and are the main source of thalamic input to the striatum (Galvan and Smith, 2011). The midline and intralaminar nuclei have other projection targets (e.g., the hippocampus and amygdala), and modulators in these nuclei can therefore influence networks beyond those directly involved in executive function.

Many open questions remain regarding the function of the midline and intralaminar nuclei. In most cases we lack even basic information, such as which area (or areas) drives these nuclei, or what are the receptive field properties of their cells. Nonetheless, some of the nuclei have been implicated in functional loops in which modulators play a critical role. I will review those here.

One of the first functions proposed for the midline and intralaminar nuclei, and in which modulators are involved, was state maintenance. Moruzzi and Magoun's (1949) classic study raised the possibility that the intralaminar nuclei could mediate the effect of the reticular activating system on the neocortex during wakefulness. The cortical projections of the midline and intralaminar nuclei, which innervate the superficial layers of multiple regions, gave support to the idea that the reticular activating system could influence neocortex through the activation 
of the midline-intralaminar thalamus. This is consistent with the disruption of consciousness that follows damage to this thalamic region in humans (Llinás et al., 1998), as well as with the improvement that follows deep brain stimulation of the intralaminar nuclei in patients in the minimally conscious state (Schiff et al., 2007). Likewise, brainstem cholinergic and monoaminergic regions promote wakefulness through their effect on multiple regions (Lee and Dan, 2012), and they innervate midline and intralaminar nuclei extensively (reviewed above). On the other hand, the traditional view of a brainstem-midline/intralaminar-neocortex network that implements wakefulness has recently been challenged (Fuller et al., 2011). According to Fuller et al. (2011) one of the relevant networks for state regulation starts on parabrachial glutamatergic afferents that project to the basal forebrain, which then influences neocortical state directly, and could also do so indirectly through the thalamus (Hallanger et al., 1987; Buzsaki et al., 1988; Parent et al., 1988; Steriade et al., 1988; Gritti et al., 1998). The role of the intralaminar and midline nuclei in state maintenance needs further clarification. New experimental strategies to manipulate the activity of specific pathways ( $\mathrm{Xu}$ and Südhof, 2013) offer more selective approaches to attack this question.

Regarding cognitive behavior, the modulation of the midline and intralaminar nuclei may be important in rewarded behavior. These nuclei have high densities of dopamine D2 receptors compared to other parts of the thalamus (Rieck et al., 2004; Piggott et al., 2007); dopamine can influence the midline and intralaminar nuclei locally, but dopaminergic modulation of midline output is likely to also occur at striatal and mPFC targets. Paraventricular and dopaminergic terminals converge, in close spatial relation, onto the same cells in the nucleus accumbens, although that close relation was not found in $\mathrm{mPFC}$ (Pinto et al., 2003). Instead, centromedian terminals in the striatum were not found on the same postsynaptic dendrites as dopaminergic terminals (Smith et al., 1994). In mPFC, mediodorsal afferents converge on the same layer $\mathrm{V}$ cells contacted by dopaminergic axons, with the mediodorsal input being more distal to the soma (Kuroda et al., 1996). The anatomical data indicates that the paraventricular nucleus has the closest synaptic relation with dopaminergic terminals. The paraventricular nucleus has been suggested to participate in dopamine-mediated reward associations (Igelstrom et al., 2010; Choi et al., 2012; Martin-Fardon and Boutrel, 2012). Kelley et al. (2005) proposed that the paraventricular nucleus is an important component of the network controlling food-related, goal-directed behavior. The paraventricular would integrate energy and circadian information from the hypothalamic orexin system and relay it to the striatum to regulate dopamine levels and feeding behavior, a hypothesis that has recently received support in rats (Choi et al., 2012). In fact, the paraventricular is the thalamic nucleus with the densest orexinergic innervation (Sakurai, 2007), and the effect of these peptides on paraventricular networks deserves further investigation. The role of other nuclei in the midline and intralaminar groups (which also respond to orexins) on rewarded behavior is largely unexplored (Purvis and Duncan, 1997; Bayer et al., 2002).

Recent evidence points to another important function of the caudal intralaminar group in behavioral flexibility and task switching in relation to sensory demands (Galvan and Smith,
2011). Lesions or inactivation of the parafascicular nucleus impair tasks that require behavioral flexibility and prevent the local increase in acetylcholine that occurs in the dorsal striatum during task shifting (Brown et al., 2010; Kato et al., 2011). Thalamostriatal afferents evoke a burst-pause firing pattern in striatal cholinergic interneurons; the cholinergic burst transiently silences corticostriatal afferents (Figure 5), and is followed by a facilitation of the striatopallidal output, which is thought to contribute to action suppression through the motor thalamus. This brief overriding of corticostriatal input followed by the biased activation of the striatopallidal "no-go" pathway, is thought to suppress ongoing motor output and allow for the selection of a different action (Ding et al., 2010). A complementary line of evidence indicates that intralaminar cells respond with burst discharges to a variety of stimuli, particularly to unexpected and salient stimuli, and could therefore play an important role in shifting attention and behavior under unexpected or changing conditions (Matsumoto et al., 2001), which would contribute to the deficits in cue-triggered responses observed after intralaminar lesions (Hembrook and Mair, 2011). An important experiment will be to determine if it is specifically the burst firing mode in intralaminar cells that evokes burst-pause firing in striatal cholinergic interneurons. Acetylcholine selectively hyperpolarizes intralaminar cells that project to striatum (Beatty et al., 2009) and this modulator could be critical at influencing behavioral flexibility at the thalamic level by keeping intralaminar cells in burst mode. Also interesting is that thalamostriatal projections from the caudal intralaminar nuclei

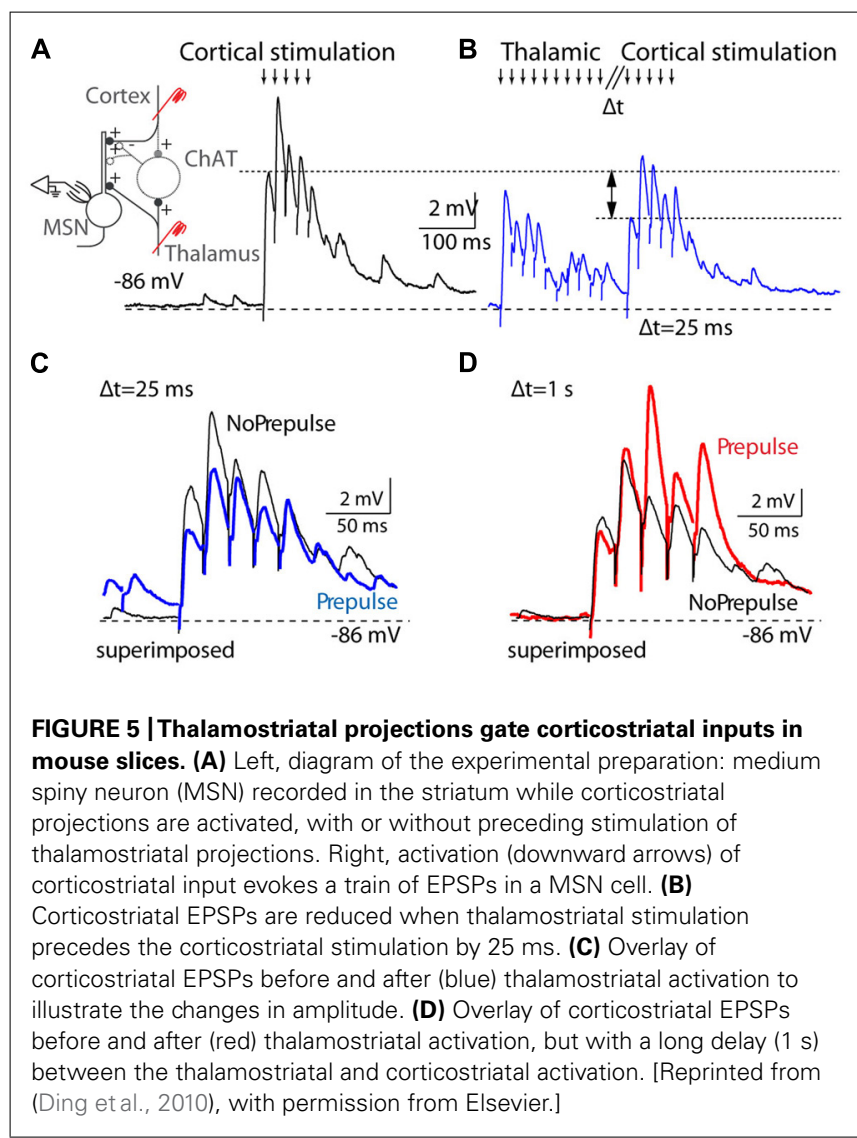


are largely segregated from thalamocortical projections, whereas in the rostral intralaminar and outside of the intralaminar group, projections often collateralize to cortex and striatum (Smith et al., 2009). This suggests that modulation may occur selectively and independently for the thalamostriatal and thalamocortical caudal intralaminar networks.

Within the midline group, a few studies implicate the nucleus reuniens in behavioral flexibility and other cognitive processes (reviewed in: Cassel et al., 2013). In a water maze task, Dollemanvan der Weel et al. (2009) observed that reuniens lesions in rats did not alter memory acquisition, but made the animals more "impulsive" during retrieval. In probe trials, animals searched for the platform in the correct location, but, in contrast to controls, soon switched to searching all over the pool. Impulsive responses were also observed after reuniens lesions in rats in a multiple choice visual-response task (Prasad etal., 2013), although not in a similar task used by Hembrook and Mair (2011). Consistent with a role in behavioral flexibility, inactivation of reuniens produced deficits in behavioral paradigms that required response inhibition, like the passive avoidance task (Davoodi et al., 2011) and a task that required switching from egocentric to allocentric navigation strategies (Cholvin et al., 2013). An important confound is that inactivation of reuniens can have additional effects, such as impairment of working memory (Hallock et al., 2013) and enhancement of memory generalization (Xu and Südhof, 2013), which could produce impairments in cognitive flexibility. Outside of reuniens, there is some evidence that the mediodorsal nucleus may contribute to behavioral flexibility; inactivation of this nucleus leads to perseverative errors in a task that required rats to switch from egocentric to cue-discrimination strategies (Block et al., 2007). More research is needed to clarify the role of the midline thalamus in behavioral flexibility and to begin the exploration of thalamic modulation on this function. Evidence from $\mathrm{mPFC}$ (a major target of the midline nuclei) indicates an important role for dopamine in behavioral flexibility (Floresco and Magyar, 2006) and makes this modulator an inviting starting point.

\section{SUMMARY AND FUTURE DIRECTIONS}

Most modulators have relatively similar properties within first order thalamic nuclei, but differ in either their anatomical or functional features between first and higher order. Table 1 summarizes the key anatomical and physiological findings in first and higher order nuclei, as well as those specific to the midline and intralaminar areas. Higher order nuclei receive glutamatergic modulators from the lower sublamina of layer VI, they receive cholinergic input with a larger LDT component than first order, they have subsets of cells that are hyperpolarized by acetylcholine and serotonin, and receive denser projections from brainstem modulators (cholinergic, serotonergic, noradrenergic, and dopaminergic). Many higher order nuclei have not been extensively studied, and further research is needed to advance our understanding of the similarities and differences across nuclei, and to fully characterize their functional implications.

One crucial aspect that has been minimally investigated in the thalamus is the integration of modulator and driver inputs in individual dendrites (although see Crandall and Cox, 2013). The view of thalamic cells as relays has been so prevalent in the literature, that complementary conceptual frameworks have been weakened or not even considered. Thinking of thalamic cells as relays is important to understand thalamic function, but other views are necessary and will stir further progress on our understanding of the thalamus. The careful organization of thalamic modulator and driver synapses along the dendrites of thalamic cells suggests an important role for thalamic cells in the integration of inputs. Corticothalamic modulators have small terminals that tend to contact relatively distal parts of the dendrites of thalamic cells. Other modulators (cholinergic, serotonergic) spread their synapses along the proximal dendrites, falling within the area of termination of drivers. The overlap of synapses in proximal dendrites may facilitate the modulation of drivers and of voltage dependent channels (such as $\mathrm{I}_{\mathrm{T}}$ ) located in those dendritic regions (Destexhe et al., 1998). The overlap between drivers and modulators is particularly relevant in higher order nuclei; these nuclei have drivers of multiple origins (Baldauf et al., 2005; Masterson et al., 2009) that could be modulated independently, something that needs to be investigated. Furthermore, the arrangement of synapses along the dendrites of thalamic cells may be important to ensure adequate interactions between modulators. Recording from thalamic dendrites is feasible (Williams and Stuart, 2000), and recent advancements in multicolor optogenetics (Klapoetke et al., 2014) allow the specific manipulation of multiple modulator populations. Studying the interaction of multiple modulators on individual dendrites is critical to figuring out their relative contribution to cell physiology, their influence on other inputs and, ultimately, the computational functions of thalamic cells.

By far, the most broadly studied effect of thalamic modulators has been the effect on membrane potential. This focus is well justified, since changing the membrane potential switches thalamic cells between the linear "tonic" mode of response (at depolarized levels) and the non-linear "burst" mode (at hyperpolarized membrane potentials). The tonic mode is thought to be an accurate mode of information transmission, whereas the burst mode has a higher signal-to-noise ratio and can be more effective at indicating a change in incoming information. This has important implications for the gating functions of thalamic nuclei through the sleep-wake cycle, and for the generation of oscillatory rhythms in thalamocortical networks. Rhythmic burst firing due to abnormal inhibition has been suggested to interfere with thalamic function and contribute to the pathophysiology of neuropsychiatric disorders, such as schizophrenia (Llinás et al., 1999; Lisman, 2012). Some modulators (acetylcholine, serotonin) specifically inhibit cells in higher order nuclei, and dysfunction of these modulators could contribute to abnormal rhythmicity in these nuclei. The effect of modulators on membrane potential also has implications for gain control, as suggested by layer VI modulation results in the visual system. Gain control at the thalamic level could represent a form of top-down control on earlier stages of the visual pathway, like the LGN, which receive layer VI afferents from the cortical regions that they project to. Future experiments will determine if layer VI projections to the thalamus can have gain control functions in higher order nuclei. These nuclei 


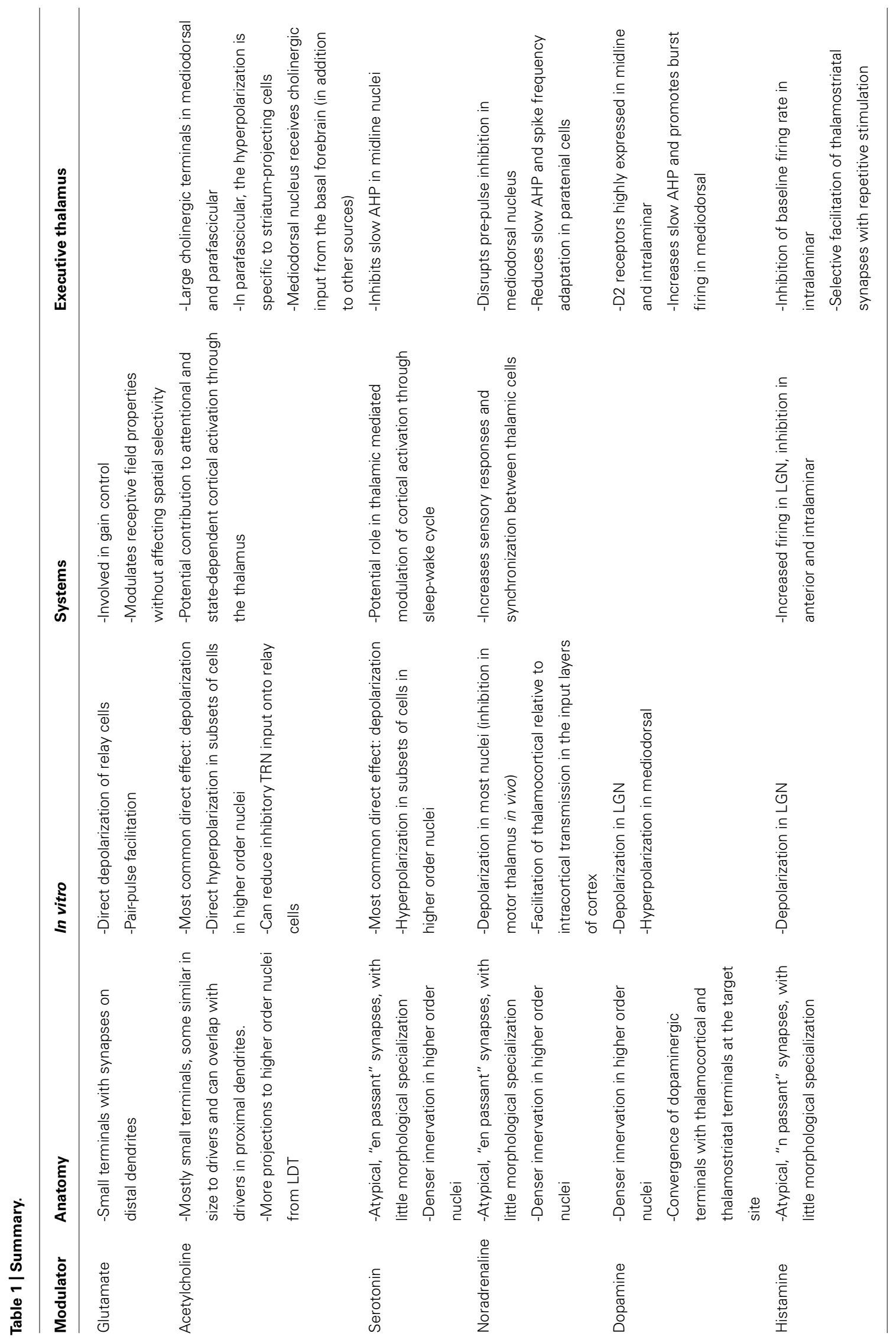


receive reciprocal (from cortical regions they project to) and nonreciprocal (from cortical regions they receive driver input from) layer VI afferents that could contribute, respectively, to top-down and bottom-up mechanisms of gain control. Furthermore, beyond the role of modulators on excitability, there is evidence that modulators influence the response properties of relay cells through the modification of the voltage-dependence of membrane conductances (e.g., the blockade of sAHP by serotonin and noradrenaline; McCormick and Prince, 1988; Goaillard and Vincent, 2002). However, the effect of these changes in the encoding of information in the awake animal is not known.

Undoubtedly, much remains to be learned about thalamic modulation from the systems perspective. Brainstem modulators experience state dependent changes in activity, and, within states, modulators could contribute to further fine-tuning, e.g., to variations in alertness. Investigation of higher order nuclei in different behavioral states could be an effective starting point. For example, during wakefulness, higher order relay cells are more likely to fire bursts than first order relay cells (Ramcharan et al., 2005), as predicted from the in vitro data reviewed here. However, we do not know what changes occur in higher order nuclei throughout the sleep-wake cycle, although their strong innervation from brainstem state regulation centers suggests stronger modulations than in first order nuclei.

Within the higher order nuclei, the midline and intralaminar groups stand out as essential components of the executive networks that engage mPFC and basal ganglia. Research in these thalamic groups has lagged behind the study of the sensory thalamus. Recent evidence suggests that these nuclei have a role in modulator regulated behaviors, such as behavioral flexibility and reward directed behavior. Research in this part of the thalamus is essential to understanding executive behavior and disease. The thalamus has been a successful therapeutic target for deep brain stimulation in a number of neurological conditions, such as essential tremor (Lyons, 2011). Treatments for disorders of executive function (schizophrenia, depression) will not be able to take the thalamus into account until we understand the role of nuclei like the midline and intralaminar in executive networks.

\section{ACKNOWLEDGMENT}

I thank M. J. Galazo and A. Rosenberg for their helpful feedback on this manuscript.

\section{REFERENCES}

Abramson, B. P., and Chalupa, L. M. (1985). The laminar distribution of cortical connections with the tecto- and cortico-recipient zones in the cat's lateral posterior nucleus. Neuroscience 15, 81-95. doi: 10.1016/0306-4522(85) 90125-3

Albrecht, D., Quäschling, U., Zippel, U., and Davidowa, H. (1996). Effects of dopamine on neurons of the lateral geniculate nucleus: an iontophoretic study. Synapse 23, 70-78. doi: 10.1002/(SICI) 1098-2396(199606)23:2<70::AIDSYN2>3.0.CO;2-D

Alexander, G. M., Fisher, T. L., and Godwin, D. W. (2006). Differential response dynamics of corticothalamic glutamatergic synapses in the lateral geniculate nucleus and thalamic reticular nucleus. Neuroscience 137, 367-372. doi: 10.1016/j.neuroscience.2005.11.012

Alexander, G. M., and Godwin, D. W. (2005). Presynaptic inhibition of corticothalamic feedback by metabotropic glutamate receptors. J. Neurophysiol. 94, 163-175. doi: $10.1152 /$ jn. 01198.2004
Alloway, K. D., Olson, M. L., and Smith, J. B. (2008). Contralateral corticothalamic projections from MI whisker cortex: potential route for modulating hemispheric interactions. J. Comp. Neurol. 510, 100-116. doi: 10.1002/cne. 21782

Alsene, K. M., Rajbhandari, A. K., Ramaker, M. J., and Bakshi, V. P. (2011). Discrete forebrain neuronal networks supporting noradrenergic regulation of sensorimotor gating. Neuropsychopharmacology 36, 1003-1014. doi: 10.1038/npp. 2010.238

Baldauf, Z. B., Wang, S., Chomsung, R. D., May, P. J., and Bickford, M. E. (2005). Ultrastructural analysis of projections to the pulvinar nucleus of the cat. II: Pretectum. J. Comp. Neurol. 485, 108-126. doi: 10.1002/cne.20487

Bartlett, E. L., Stark, J. M., Guillery, R. W., and Smith, P. H. (2000). Comparison of the fine structure of cortical and collicular terminals in the rat medial geniculate body. Neuroscience 100, 811-828. doi: 10.1016/S0306-4522(00) 00340-7

Bayer, L., Eggermann, E., Saint-Mleux, B., Machard, D., Jones, B. E., Mühlethaler, M., et al. (2002). Selective action of orexin (hypocretin) on nonspecific thalamocortical projection neurons. J. Neurosci. 22, 7835-7839.

Beatty, J. A., Sylwestrak, E. L., and Cox, C. L. (2009). Two distinct populations of projection neurons in the rat lateral parafascicular thalamic nucleus and their cholinergic responsiveness. Neuroscience 162, 155-173. doi: 10.1016/j.neuroscience.2009.04.043

Bender, D. B., and Youakim, M. (2001). Effect of attentive fixation in macaque thalamus and cortex. J. Neurophysiol. 85, 219-234.

Bickford, M. E., Günlük, A. E., Guido, W., and Sherman, S. M. (1993). Evidence that cholinergic axons from the parabrachial region of the brainstem are the exclusive source of nitric oxide in the lateral geniculate nucleus of the cat. J. Comp. Neurol. 334, 410-430. doi: 10.1002/cne.903340307

Bickford, M. E., Ramcharan, E., Godwin, D. W., Erisir, A., Gnadt, J., and Sherman, S. M. (2000). Neurotransmitters contained in the subcortical extraretinal inputs to the monkey lateral geniculate nucleus. J. Comp. Neurol. 424, 701-717. doi: 10.1002/1096-9861(20000904)424:4<701::AID-CNE11>3.0.CO;2-B

Billet, S., Cant, N. B., and Hall, W. C. (1999). Cholinergic projections to the visual thalamus and superior colliculus. Brain Res. 847, 121-123. doi: 10.1016/S00068993(99)01900-9

Blandina, P., Munari, L., Provensi, G., and Passani, M. B. (2012). Histamine neurons in the tuberomamillary nucleus: a whole center or distinct subpopulations? Front. Syst. Neurosci. 6:33. doi: 10.3389/fnsys.2012.00033

Block, A. E., Dhanji, H., Thompson-Tardif, S. F., and Floresco, S. B. (2007). Thalamic-prefrontal cortical-ventral striatal circuitry mediates dissociable components of strategy set shifting. Cereb. Cortex 17, 1625-1636. doi: 10.1093/cercor/bhl073

Bolton, R. F., Cornwall, J., and Phillipson, O. T. (1993). Collateral axons of cholinergic pontine neurones projecting to midline, mediodorsal and parafascicular thalamic nuclei in the rat. J. Chem. Neuroanat. 6, 101-114. doi: 10.1016/0891-0618(93)90031-X

Bourassa, J., and Deschênes, M. (1995). Corticothalamic projections from the primary visual cortex in rats: a single fiber study using biocytin as an anterograde tracer. Neuroscience 66, 253-263. doi: 10.1016/0306-4522(95) 00009-8

Bourassa, J., Pinault, D., and Deschênes, M. (1995). Corticothalamic projections from the cortical barrel field to the somatosensory thalamus in rats: a single-fibre study using biocytin as an anterograde tracer. Eur. J. Neurosci. 7, 19-30. doi: 10.1111/j.1460-9568.1995.tb01016.x

Briggs, F. (2010). Organizing principles of cortical layer 6. Front. Neural Circuits 4:3. doi: 10.3389/neuro.04.003.2010

Briggs, F., and Usrey, W. M. (2011). Corticogeniculate feedback and visual processing in the primate. J. Physiol. (Lond.) 589, 33-40. doi: 10.1113/jphysiol.2010.193599

Brown, H. D., Baker, P. M., and Ragozzino, M. E. (2010). The parafascicular thalamic nucleus concomitantly influences behavioral flexibility and dorsomedial striatal acetylcholine output in rats. J. Neurosci. 30, 14390-14398. doi: 10.1523/JNEUROSCI.2167-10.2010

Buzsaki, G., Bickford, R. G., Ponomareff, G., Thal, L. J., Mandel, R., and Gage, F. H. (1988). Nucleus basalis and thalamic control of neocortical activity in the freely moving rat. J. Neurosci. 8, 4007-4026.

Byrum, C. E., and Guyenet, P. G. (1987). Afferent and efferent connections of the A5 noradrenergic cell group in the rat. J. Comp. Neurol. 261, 529-542. doi: $10.1002 /$ cne. 902610406 
Cappe, C., Morel, A., and Rouiller, E. M. (2007). Thalamocortical and the dual pattern of corticothalamic projections of the posterior parietal cortex in macaque monkeys. Neuroscience 146, 1371-1387. doi: 10.1016/j.neuroscience.2007. 02.033

Cassel, J.-C., Pereira de Vasconcelos, A., Loureiro, M., Cholvin, T., Dalrymple-Alford, J. C., and Vertes, R. P. (2013). The reuniens and rhomboid nuclei: neuroanatomy, electrophysiological characteristics and behavioral implications. Prog. Neurobiol. 111, 34-52. doi: 10.1016/j.pneurobio.2013.08.006

Cenquizca, L. A., and Swanson, L. W. (2006). An analysis of direct hippocampal cortical field CAl axonal projections to diencephalon in the rat. J. Comp. Neurol. 497, 101-114. doi: 10.1002/cne.20985

Chapin, E. M., and Andrade, R. (2001a). A 5-HT(7) receptor-mediated depolarization in the anterodorsal thalamus. I. Pharmacological characterization. J. Pharmacol. Exp. Ther. 297, 395-402.

Chapin, E. M., and Andrade, R. (2001b). A 5-HT(7) receptor-mediated depolarization in the anterodorsal thalamus. II. Involvement of the hyperpolarizationactivated current I(h). J. Pharmacol. Exp. Ther. 297, 403-409.

Choi, D. L., Davis, J. F., Magrisso, I. J., Fitzgerald, M. E., Lipton, J. W., and Benoit, S. C. (2012). Orexin signaling in the paraventricular thalamic nucleus modulates mesolimbic dopamine and hedonic feeding in the rat. Neuroscience 210, 243-248. doi: 10.1016/j.neuroscience.2012.02.036

Cholvin, T., Loureiro, M., Cassel, R., Cosquer, B., Geiger, K., De Sa Nogueira, D., et al. (2013). The ventral midline thalamus contributes to strategy shifting in a memory task requiring both prefrontal cortical and hippocampal functions. I. Neurosci. 33, 8772-8783. doi: 10.1523/JNEUROSCI.0771-13.2013

Clascá, F., Rubio-Garrido, P., and Jabaudon, D. (2012). Unveiling the diversity of thalamocortical neuron subtypes. Eur. J. Neurosci. 35, 1524-1532. doi: 10.1111/j.1460-9568.2012.08033.x

Conley, M., and Raczkowski, D. (1990). Sublaminar organization within layer VI of the striate cortex in Galago. J. Comp. Neurol. 302, 425-436. doi: 10.1002/cne.903020218

Cornwall, J., and Phillipson, O. T. (1988). Afferent projections to the dorsal thalamus of the rat as shown by retrograde lectin transport. II. The midline nuclei. Brain Res. Bull. 21, 147-161. doi: 10.1016/0361-9230(88)90227-4

Crandall, S. R., and Cox, C. L. (2013). Thalamic microcircuits: presynaptic dendrites form two feedforward inhibitory pathways in thalamus. J. Neurophysiol. 110, 470-480. doi: 10.1152/jn.00559.2012

Cropper, E. C., Eisenman, J. S., and Azmitia, E. C. (1984). An immunocytochemical study of the serotonergic innervation of the thalamus of the rat. J. Comp. Neurol. 224, 38-50. doi: 10.1002/cne.902240104

Cucchiaro, J. B., Uhlrich, D. J., and Sherman, S. M. (1988). Parabrachial innervation of the cat's dorsal lateral geniculate nucleus: an electron microscopic study using the tracer Phaseolus vulgaris leucoagglutinin (PHA-L). J. Neurosci. 8, 45764588 .

Cudeiro, J., and Sillito, A. M. (2006). Looking back: corticothalamic feedback and early visual processing. Trends Neurosci. 29, 298-306. doi: 10.1016/j.tins.2006.05.002

Curró Dossi, R., Paré, D., and Steriade, M. (1991). Short-lasting nicotinic and long-lasting muscarinic depolarizing responses of thalamocortical neurons to stimulation of mesopontine cholinergic nuclei. J. Neurophysiol. 65, 393-406.

Davoodi, F. G., Motamedi, F., Akbari, E., Ghanbarian, E., and Jila, B. (2011). Effect of reversible inactivation of reuniens nucleus on memory processing in passive avoidance task. Behav. Brain Res. 221, 1-6. doi: 10.1016/j.bbr.2011. 02.020

De Lima, A. D., and Singer, W. (1987). The brainstem projection to the lateral geniculate nucleus in the cat: identification of cholinergic and monoaminergic elements. J. Comp. Neurol. 259, 92-121. doi: 10.1002/cne.902590107

Dekker, J. J., and Kuypers, H. G. (1976). Quantitative EM study of projection terminal in the rats AV thalamic nucleus. Autoradiographic and degeneration techniques compared. Brain Res. 117, 399-422. doi: 10.1016/0006-8993(76)90750-2

Destexhe, A., Neubig, M., Ulrich, D., and Huguenard, J. (1998). Dendritic lowthreshold calcium currents in thalamic relay cells. J. Neurosci. 18, 3574-3588.

Devilbiss, D. M., and Waterhouse, B. D. (2011). Phasic and tonic patterns of locus coeruleus output differentially modulate sensory network function in the awake rat. J. Neurophysiol. 105, 69-87. doi: 10.1152/jn.00445.2010

Ding, J. B., Guzman, J. N., Peterson, J. D., Goldberg, J. A., and Surmeier, D. J. (2010). Thalamic gating of corticostriatal signaling by cholinergic interneurons. Neuron 67, 294-307. doi: 10.1016/j.neuron.2010.06.017
Dolleman-van der Weel, M. J., Morris, R. G. M., and Witter, M. P. (2009). Neurotoxic lesions of the thalamic reuniens or mediodorsal nucleus in rats affect non-mnemonic aspects of watermaze learning. Brain Struct. Funct. 213, 329-342. doi: 10.1007/s00429-008-0200-6

Ellender, T. J., Huerta-Ocampo, I., Deisseroth, K., Capogna, M., and Bolam, J. P. (2011). Differential modulation of excitatory and inhibitory striatal synaptic transmission by histamine. J. Neurosci. 31, 15340-15351. doi: 10.1523/JNEUROSCI.3144-11.2011

Erisir, A., Van Horn, S. C., Bickford, M. E., and Sherman, S. M. (1997a). Immunocytochemistry and distribution of parabrachial terminals in the lateral geniculate nucleus of the cat: a comparison with corticogeniculate terminals. J. Comp. Neurol. 377, 535-549. doi: 10.1002/(SICI)1096-9861(19970127)377:4<535::AIDCNE5 $>3.0 . \mathrm{CO} ; 2-3$

Erisir, A., Van Horn, S. C., and Sherman, S. M. (1997b). Relative numbers of cortical and brainstem inputs to the lateral geniculate nucleus. Proc. Natl. Acad. Sci. U.S.A. 94, 1517-1520. doi: 10.1073/pnas.94.4.1517

Favero, M., Varghese, G., and Castro-Alamancos, M. A. (2012). The state of somatosensory cortex during neuromodulation. J. Neurophysiol. 108, 1010-1024. doi: 10.1152/jn.00256.2012

Fitzpatrick, D., Conley, M., Luppino, G., Matelli, M., and Diamond, I. T. (1988). Cholinergic projections from the midbrain reticular formation and the parabigeminal nucleus to the lateral geniculate nucleus in the tree shrew. J. Comp. Neurol. 272, 43-67. doi: 10.1002/cne.902720105

Fitzpatrick, D., Diamond, I. T., and Raczkowski, D. (1989). Cholinergic and monoaminergic innervation of the cat's thalamus: comparison of the lateral geniculate nucleus with other principal sensory nuclei. J. Comp. Neurol. 288, 647-675. doi: 10.1002/cne.902880411

Floresco, S. B., and Magyar, O. (2006). Mesocortical dopamine modulation of executive functions: beyond working memory. Psychopharmacology (Berl.) 188, 567-585. doi: 10.1007/s00213-006-0404-5

Francesconi, W., Müller, C. M., and Singer, W. (1988). Cholinergic mechanisms in the reticular control of transmission in the cat lateral geniculate nucleus. J. Neurophysiol. 59, 1690-1718.

Fuller, P. M., Sherman, D., Pedersen, N. P., Saper, C. B., and Lu, J. (2011). Reassessment of the structural basis of the ascending arousal system. J. Comp. Neurol. 519, 933-956. doi: 10.1002/cne.22559

Galvan, A., and Smith, Y. (2011). The primate thalamostriatal systems: anatomical organization, functional roles and possible involvement in Parkinson's disease. Basal Ganglia 1, 179-189. doi: 10.1016/j.baga.2011.09.001

García-Cabezas, M. A., Martínez-Sánchez, P., Sánchez-González, M. A., Garzón, M., and Cavada, C. (2009). Dopamine innervation in the thalamus: monkey versus rat. Cereb. Cortex 19, 424-434. doi: 10.1093/cercor/bhn093

Giguere, M., and Goldman-Rakic, P. S. (1988). Mediodorsal nucleus: areal, laminar, and tangential distribution of afferents and efferents in the frontal lobe of rhesus monkeys. J. Comp. Neurol. 277, 195-213. doi: 10.1002/cne.902770204

Goaillard, J.-M., and Vincent, P. (2002). Serotonin suppresses the slow afterhyperpolarization in rat intralaminar and midline thalamic neurones by activating 5-HT(7) receptors. J. Physiol. (Lond.) 541, 453-465. doi: 10.1113/jphysiol.2001.013896

Godwin, D. W., Van Horn, S. C., Eriir, A., Sesma, M., Romano, C., and Sherman, S. M. (1996). Ultrastructural localization suggests that retinal and cortical inputs access different metabotropic glutamate receptors in the lateral geniculate nucleus. J. Neurosci. 16, 8181-8192.

Gonzalo-Ruiz, A., Lieberman, A. R., and Sanz-Anquela, J. M. (1995). Organization of serotoninergic projections from the raphé nuclei to the anterior thalamic nuclei in the rat: a combined retrograde tracing and 5-HT immunohistochemical study. J. Chem. Neuroanat. 8, 103-115. doi: 10.1016/0891-0618(94)00039-V

Govindaiah, G., and Cox, C. L. (2005). Excitatory actions of dopamine via D1-like receptors in the rat lateral geniculate nucleus. J. Neurophysiol. 94, 3708-3718. doi: 10.1152/jn.00583.2005

Govindaiah, G., Wang, T., Gillette, M. U., Crandall, S. R., and Cox, C. L. (2010). Regulation of inhibitory synapses by presynaptic $\mathrm{D}_{4}$ dopamine receptors in thalamus. J. Neurophysiol. 104, 2757-2765. doi: 10.1152/jn.00361.2010

Grasso, C., Li Volsi, G., Licata, F., Ciranna, L., and Santangelo, F. (2006). Aminergic control of neuronal firing rate in thalamic motor nuclei of the rat. Arch. Ital. Biol. 144, 173-196.

Gritti, I., Mariotti, M., and Mancia M. (1998). GABAergic and cholinergic basal forebrain and preoptic-anterior hypothalamic projections to the mediodorsal 
nucleus of the thalamus in the cat. Neuroscience 85, 149-178. doi: 10.1016/S03064522(97)00573-3

Groenewegen, H. J. (1988). Organization of the afferent connections of the mediodorsal thalamic nucleus in the rat, related to the mediodorsal-prefrontal topography. Neuroscience 24, 379-431. doi: 10.1016/0306-4522(88)90339-9

Guillery, R. W. (1995). Anatomical evidence concerning the role of the thalamus in corticocortical communication: a brief review. J. Anat. 187(Pt 3), 583-592.

Guillery, R. W., and Sherman, S. M. (2002). Thalamic relay functions and their role in corticocortical communication: generalizations from the visual system. Neuron 33, 163-175. doi: 10.1016/S0896-6273(01)00582-7

Gutierrez, C., Cox, C. L., Rinzel, J., and Sherman, S. M. (2001). Dynamics of lowthreshold spike activation in relay neurons of the cat lateral geniculate nucleus. J. Neurosci. 21, 1022-1032.

Hallanger, A. E., Levey, A. I., Lee, H. J., Rye, D. B., and Wainer, B. H. (1987). The origins of cholinergic and other subcortical afferents to the thalamus in the rat. J. Comp. Neurol. 262, 105-124. doi: 10.1002/cne.902620109.

Hallanger, A. E., Price, S. D., Lee, H. J., Steininger, T. L., and Wainer, B. H. (1990) Ultrastructure of cholinergic synaptic terminals in the thalamic anteroventral, ventroposterior, and dorsal lateral geniculate nuclei of the rat. J. Comp. Neurol. 299, 482-492. doi: 10.1002/cne.902990408

Hallock, H. L., Wang, A., Shaw, C. L., and Griffin, A. L. (2013). Transient inactivation of the thalamic nucleus reuniens and rhomboid nucleus produces deficits of a working-memory dependent tactile-visual conditional discrimination task. Behav. Neurosci. 127, 860-866. doi: 10.1037/a0034653

Hazama, M., Kimura, A., Donishi, T., Sakoda, T., and Tamai, Y. (2004). Topography of corticothalamic projections from the auditory cortex of the rat. Neuroscience 124, 655-667. doi: 10.1016/j.neuroscience.2003.12.027

Heckers, S., Geula, C., and Mesulam, M. M. (1992). Cholinergic innervation of the human thalamus: dual origin and differential nuclear distribution. J. Comp. Neurol. 325, 68-82. doi: 10.1002/cne.903250107

Hembrook, J. R., and Mair, R. G. (2011). Lesions of reuniens and rhomboid thalamic nuclei impair radial maze win-shift performance. Hippocampus 21, 815-826. doi: 10.1002/hipo.20797

Hobson, J. A., Stickgold, R., and Pace-Schott, E. F. (1998). The neuropsychology of REM sleep dreaming. Neuroreport 9, R1-R14. doi: 10.1097/00001756199802160-00033

Hoover, W. B., and Vertes, R. P. (2007). Anatomical analysis of afferent projections to the medial prefrontal cortex in the rat. Brain Struct. Funct. 212, 149-179. doi: 10.1007/s00429-007-0150-4

Hu, B., Steriade, M., and Deschênes, M. (1989). The effects of brainstem peribrachial stimulation on perigeniculate neurons: the blockage of spindle waves. Neuroscience 31, 1-12. doi: 10.1016/0306-4522(89)90026-2

Hughes, H. C., and Mullikin, W. H. (1984). Brainstem afferents to the lateral geniculate nucleus of the cat. Exp. Brain Res. 54, 253-258. doi: 10.1007/BF00236224

Igelstrom, K. M., Herbison, A. E., and Hyland, B. I. (2010). Enhanced cFos expression in superior colliculus, paraventricular thalamus and septum during learning of cue-reward association. Neuroscience 168, 706-714. doi: 10.1016/j.neuroscience.2010.04.018

Jacobson, S., and Trojanowski, J. Q. (1975). Corticothalamic neurons and thalamocortical terminal fields: an investigation in rat using horseradish peroxidase and autoradiography. Brain Res. 85, 385-401. doi: 10.1016/0006-8993(75)90815-X

Jahnsen, H., and Llinás, R. (1984). Electrophysiological properties of guinea-pig thalamic neurones: an in vitro study. J. Physiol. (Lond.) 349, 205-226.

Jones, E. G. (2007). The Thalamus 1. Cambridge: Cambridge University Press.

Jones, H. E., Andolina, I. M., Ahmed, B., Shipp, S. D., Clements, J. T. C., Grieve, K. L., et al. (2012). Differential feedback modulation of center and surround mechanisms in parvocellular cells in the visual thalamus. J. Neurosci. 32, 1594615951. doi: 10.1523/JNEUROSCI.0831-12.2012

Jurgens, C. W. D., Bell, K. A., McQuiston, A. R., and Guido, W. (2012). Optogenetic stimulation of the corticothalamic pathway affects relay cells and GABAergic neurons differently in the mouse visual thalamus. PLOS ONE 7:e45717. doi: 10.1371/journal.pone.0045717

Kaitz, S. S., and Robertson, R. T. (1981). Thalamic connections with limbic cortex. II. Corticothalamic projections. J. Comp. Neurol. 195, 527-545. doi: 10.1002/cne.901950309

Kakei, S., Na, J., and Shinoda, Y. (2001). Thalamic terminal morphology and distribution of single corticothalamic axons originating from layers 5 and 6 of the cat motor cortex. J. Comp. Neurol. 437, 170-185. doi: 10.1002/cne.1277
Kato, S., Kuramochi, M., Kobayashi, K., Fukabori, R., Okada, K., Uchigashima, M., et al. (2011). Selective neural pathway targeting reveals key roles of thalamostriatal projection in the control of visual discrimination. J. Neurosci. 31, 17169-17179. doi: 10.1523/JNEUROSCI.4005-11.2011

Kawai, H., Lazar, R., and Metherate, R. (2007). Nicotinic control of axon excitability regulates thalamocortical transmission. Nat. Neurosci. 10, 1168-1175. doi: 10.1038/nn1956

Kayama, Y., Shimada, S., Hishikawa, Y., and Ogawa, T. (1989). Effects of stimulating the dorsal raphe nucleus of the rat on neuronal activity in the dorsal lateral geniculate nucleus. Brain Res. 489, 1-11. doi: 10.1016/0006-8993(89) 90002-4

Kelley, A. E., Baldo, B. A., and Pratt, W. E. (2005). A proposed hypothalamicthalamic-striatal axis for the integration of energy balance, arousal, and food reward. J. Comp. Neurol. 493, 72-85. doi: 10.1002/cne.20769

Kelly, J. P., and Wong, D. (1981). Laminar connections of the cat's auditory cortex. Brain Res. 212, 1-15. doi: 10.1016/0006-8993(81)90027-5

Kha, H. T., Finkelstein, D. I., Pow, D. V., Lawrence, A. J., and Horne, M. K. (2000). Study of projections from the entopeduncular nucleus to the thalamus of the rat. J. Comp. Neurol. 426, 366-377. doi: 10.1002/10969861(20001023)426:3<366::AID-CNE2>3.0.CO;2-B

Kha, H. T., Finkelstein, D. I., Tomas, D., Drago, J., Pow, D. V., and Horne, M. K. (2001). Projections from the substantia nigra pars reticulata to the motor thalamus of the rat: single axon reconstructions and immunohistochemical study. J. Comp. Neurol. 440, 20-30. doi: 10.1002/cne.1367

Killackey, H. P., and Sherman, S. M. (2003). Corticothalamic projections from the rat primary somatosensory cortex. J. Neurosci. 23, 7381-7384.

Kirifides, M. L., Simpson, K. L., Lin, R. C., and Waterhouse, B. D. (2001). Topographic organization and neurochemical identity of dorsal raphe neurons that project to the trigeminal somatosensory pathway in the rat. J. Comp. Neurol. 435, 325-340. doi: 10.1002/cne.1033

Klapoetke, N. C., Murata, Y., Kim, S. S., Pulver, S. R., Birdsey-Benson, A., Cho, Y. K., et al. (2014). Independent optical excitation of distinct neural populations. Nat. Methods 11, 338-346. doi: 10.1038/nmeth.2836

Krubitzer, L. A., and Seelke, A. M. H. (2012). Cortical evolution in mammals: the bane and beauty of phenotypic variability. Proc. Natl. Acad. Sci. U.S.A. 109(Suppl. 1), 10647-10654. doi: 10.1073/pnas.1201891109

Kultas-Ilinsky, K., and Ilinsky, I. A. (1991). Fine structure of the ventral lateral nucleus (VL) of the Macaca mulatta thalamus: cell types and synaptology. J. Comp. Neurol. 314, 319-349. doi: 10.1002/cne.903140209

Kupfer, D. J., Frank, E., and Phillips, M. L. (2012). Major depressive disorder: new clinical, neurobiological, and treatment perspectives. Lancet 379, 1045-1055. doi: 10.1016/S0140-6736(11)60602-8

Kuroda, M., Murakami, K., Igarashi, H., and Okada, A. (1996). The convergence of axon terminals from the mediodorsal thalamic nucleus and ventral tegmental area on pyramidal cells in layer V of the rat prelimbic cortex. Eur. J. Neurosci. 8, 1340-1349. doi: 10.1111/j.1460-9568.1996.tb01596.x

Kuroda, M., and Price, J. L. (1991). Ultrastructure and synaptic organization of axon terminals from brainstem structures to the mediodorsal thalamic nucleus of the rat. J. Comp. Neurol. 313, 539-552. doi: 10.1002/cne.903130313

Kusnoor, S. V., Bubser, M., and Deutch, A. Y. (2012). The effects of nigrostriatal dopamine depletion on the thalamic parafascicular nucleus. Brain Res. 1446, 46-55. doi: 10.1016/j.brainres.2012.01.040

Lam, Y.-W., and Sherman, S. M. (2010). Functional organization of the somatosensory cortical layer 6 feedback to the thalamus. Cereb. Cortex 20, 13-24. doi: 10.1093/cercor/bhp077

Landisman, C. E., and Connors, B. W. (2007). VPM and PoM nuclei of the rat somatosensory thalamus: intrinsic neuronal properties and corticothalamic feedback. Cereb. Cortex 17, 2853-2865. doi: 10.1093/cercor/ bhm025

Lavin, A., and Grace, A. A. (1998). Dopamine modulates the responsivity of mediodorsal thalamic cells recorded in vitro. J. Neurosci. 18, 10566-10578.

Lavoie, B., and Parent, A. (1991). Serotoninergic innervation of the thalamus in the primate: an immunohistochemical study. J. Comp. Neurol. 312, 1-18. doi: $10.1002 / \mathrm{cne} .903120102$

Lee, H. J., Rye, D. B., Hallanger, A. E., Levey, A. I., and Wainer, B. H. (1988). Cholinergic vs. noncholinergic efferents from the mesopontine tegmentum to the extrapyramidal motor system nuclei. J. Comp. Neurol. 275, 469-492. doi: $10.1002 /$ cne. 902750402 
Lee, S., Carvell, G. E., and Simons, D. J. (2008). Motor modulation of afferent somatosensory circuits. Nat. Neurosci. 11, 1430-1438. doi: 10.1038/nn.2227

Lee, S.-H., and Dan, Y. (2012). Neuromodulation of brain states. Neuron 76, 209 222. doi: 10.1016/j.neuron.2012.09.012

Lesch, K.-P., and Waider, J. (2012). Serotonin in the modulation of neural plasticity and networks: implications for neurodevelopmental disorders. Neuron 76, 175191. doi: 10.1016/j.neuron.2012.09.013

Lévesque, M., and Parent, A. (1998). Axonal arborization of corticostriatal and corticothalamic fibers arising from prelimbic cortex in the rat. Cereb. Cortex 8, 602-613. doi: $10.1093 /$ cercor/8.7.602

Levey, A. I., Hallanger, A. E., and Wainer, B. H. (1987). Choline acetyltransferase immunoreactivity in the rat thalamus. J. Comp. Neurol. 257, 317-332. doi: $10.1002 /$ cne. 902570302

Lisman, J. (2012). Excitation, inhibition, local oscillations, or large-scale loops: what causes the symptoms of schizophrenia? Curr. Opin. Neurobiol. 22, 537-544. doi 10.1016/j.conb.2011.10.018

Liu, X. B., Honda, C. N., and Jones, E. G. (1995). Distribution of four types of synapse on physiologically identified relay neurons in the ventral posterior thalamic nucleus of the cat. J. Comp. Neurol. 352, 69-91. doi $10.1002 /$ cne. 903520106

Liu, X. B., and Jones, E. G. (1991). The fine structure of serotonin and tyrosine hydroxylase immunoreactive terminals in the ventral posterior thalamic nucleus of cat and monkey. Exp. Brain Res. 85, 507-518. doi: 10.1007/BF002 31734

Llinás, R., Ribary, U., Contreras, D., and Pedroarena, C. (1998). The neuronal basis for consciousness. Philos. Trans. R. Soc. Lond. B Biol. Sci. 353, 1841-1849. doi 10.1098/rstb.1998.0336

Llinás, R. R., Ribary, U., Jeanmonod, D., Kronberg, E., and Mitra, P. P. (1999). Thalamocortical dysrhythmia: a neurological and neuropsychiatric syndrome characterized by magnetoencephalography. Proc. Natl. Acad. Sci. U.S.A. 96, 15222-15227. doi: 10.1073/pnas.96.26.15222

Losier, B. J., and Semba, K. (1993). Dual projections of single cholinergic and aminergic brainstem neurons to the thalamus and basal forebrain in the rat. Brain Res. 604, 41-52. doi: 10.1016/0006-8993(93)90350-V

Lyons, M. K. (2011). Deep brain stimulation: current and future clinical applications. Mayo Clin. Proc. 86, 662-672. doi: 10.4065/mcp.2011.0045

MacLeod, N. K., James, T. A., and Starr, M. S. (1984). Muscarinic action of acetylcholine in the rat ventromedial thalamic nucleus. Exp. Brain Res. 55, 553-561. doi: 10.1007/BF00235286

Manning, K. A., Wilson, J. R., and Uhlrich, D. J. (1996). Histamine-immunoreactive neurons and their innervation of visual regions in the cortex, tectum, and thalamus in the primate Macaca mulatta. J. Comp. Neurol. 373, 271-282. doi 10.1002/(SICI)1096-9861(19960916)373:2<271::AID-CNE9>3.0.CO;2-0

Marks, G. A., and Roffwarg, H. P. (1989). The cholinergic influence upon rat dorsal lateral geniculate nucleus is dependent on state of arousal. Brain Res. 494, 294 306. doi: 10.1016/0006-8993(89)90598-2

Martin-Fardon, R., and Boutrel, B. (2012). Orexin/hypocretin (Orx/Hcrt) transmission and drug-seeking behavior: is the paraventricular nucleus of the thalamus (PVT) part of the drug seeking circuitry? Front. Behav. Neurosci. 6:75. doi: 10.3389/fnbeh.2012.00075

Masterson, S. P., Li, J., and Bickford, M. E. (2009). Synaptic organization of the tectorecipient zone of the rat lateral posterior nucleus. J. Comp. Neurol. 515, 647-663. doi: $10.1002 / \mathrm{cne} .22077$

Matsumoto, N., Minamimoto, T., Graybiel, A. M., and Kimura, M. (2001). Neurons in the thalamic CM-Pf complex supply striatal neurons with information about behaviorally significant sensory events. J. Neurophysiol. 85, 960-976.

Maunsell, J. H. R., and Cook, E. P. (2002). The role of attention in visual processing. Philos. Trans. R. Soc. Lond. B Biol. Sci. 357, 1063-1072. doi: 10.1098/rstb.2002.1107

McCormick, D. A. (1992). Cellular mechanisms underlying cholinergic and noradrenergic modulation of neuronal firing mode in the cat and guinea pig dorsal lateral geniculate nucleus. J. Neurosci. 12, 278-289.

McCormick, D. A., and Pape, H. C. (1988). Acetylcholine inhibits identified interneurons in the cat lateral geniculate nucleus. Nature 334, 246-248. doi: $10.1038 / 334246 a 0$

McCormick, D. A., and Pape, H. C. (1990). Noradrenergic and serotonergic modulation of a hyperpolarization-activated cation current in thalamic relay neurones. J. Physiol. (Lond.) 431, 319-342.
McCormick, D. A., and Prince, D. A. (1986). Acetylcholine induces burst firing in thalamic reticular neurones by activating a potassium conductance. Nature 319, 402-405. doi: 10.1038/319402a0

McCormick, D. A., and Prince, D. A. (1987). Actions of acetylcholine in the guineapig and cat medial and lateral geniculate nuclei, in vitro. J. Physiol. (Lond.) 392, $147-165$.

McCormick, D. A., and Prince, D. A. (1988). Noradrenergic modulation of firing pattern in guinea pig and cat thalamic neurons, in vitro. J. Neurophysiol. 59, 978-996.

McCormick, D. A., and von Krosigk, M. (1992). Corticothalamic activation modulates thalamic firing through glutamate "metabotropic" receptors. Proc. Natl. Acad. Sci. U.S.A. 89, 2774-2778. doi: 10.1073/pnas.89.7.2774

McCormick, D. A., and Williamson, A. (1991). Modulation of neuronal firing mode in cat and guinea pig LGNd by histamine: possible cellular mechanisms of histaminergic control of arousal. J. Neurosci. 11, 3188-3199.

McKenna, J. T., and Vertes, R. P. (2004). Afferent projections to nucleus reuniens of the thalamus. J. Comp. Neurol. 480, 115-142. doi: 10.1002/cne.20342

Melchitzky, D. S., Erickson, S. L., and Lewis, D. A. (2006). Dopamine innervation of the monkey mediodorsal thalamus: location of projection neurons and ultrastructural characteristics of axon terminals. Neuroscience 143, 1021-1030. doi: 10.1016/j.neuroscience.2006.08.056

Mesulam, M. M., Mufson, E. J., Wainer, B. H., and Levey, A. I. (1983). Central cholinergic pathways in the rat: an overview based on an alternative nomenclature (Ch1-Ch6). Neuroscience 10, 1185-1201. doi: 10.1016/0306-4522(83) 90108-2

Miyata, M., and Imoto, K. (2006). Different composition of glutamate receptors in corticothalamic and lemniscal synaptic responses and their roles in the firing responses of ventrobasal thalamic neurons in juvenile mice. J. Physiol. 575, 161174. doi: 10.1113/jphysiol.2006.114413

Mize, R. R., and Payne, M. P. (1987). The innervation density of serotonergic (5-HT) fibers varies in different subdivisions of the cat lateral geniculate nucleus complex. Neurosci. Lett. 82, 133-139. doi: 10.1016/0304-3940(87) 90117-0

Molinari, M., Minciacchi, D., Bentivoglio, M., and Macchi, G. (1985). Efferent fibers from the motor cortex terminate bilaterally in the thalamus of rats and cats. Exp. Brain Res. 57, 305-312. doi: 10.1007/BF00236536

Monckton, J. E., and McCormick, D. A. (2002). Neuromodulatory role of serotonin in the ferret thalamus. J. Neurophysiol. 87, 2124-2136. doi: 10.1152/jn.00650. 2001

Monti, J. M. (2011). Serotonin control of sleep-wake behavior. Sleep Med. Rev. 15, 269-281. doi: 10.1016/j.smrv.2010.11.003

Mooney, D. M., Zhang, L., Basile, C., Senatorov, V. V., Ngsee, J., Omar, A., etal. (2004). Distinct forms of cholinergic modulation in parallel thalamic sensory pathways. Proc. Natl. Acad. Sci. U.S.A. 101, 320-324. doi: 10.1073/pnas.0304445101

Morrison, J. H., and Foote, S. L. (1986). Noradrenergic and serotoninergic innervation of cortical, thalamic, and tectal visual structures in Old and New World monkeys. J. Comp. Neurol. 243, 117-138. doi: 10.1002/cne.902430110

Moruzzi, G., and Magoun, H. W. (1949). Brain stem reticular formation and activation of the EEG. Electroencephalogr. Clin. Neurophysiol. 1, 455-473. doi: 10.1016/0013-4694(49)90219-9

Moxon, K. A., Devilbiss, D. M., Chapin, J. K., and Waterhouse, B. D. (2007). Influence of norepinephrine on somatosensory neuronal responses in the rat thalamus: a combined modeling and in vivo multi-channel, multi-neuron recording study. Brain Res. 1147, 105-123. doi: 10.1016/j.brainres.2007.02.006

Murphy, P. C., Duckett, S. G., and Sillito, A. M. (1999). Feedback connections to the lateral geniculate nucleus and cortical response properties. Science 286, 1552-1554. doi: 10.1126/science.286.5444.1552

Murphy, P. C., Duckett, S. G., and Sillito, A. M. (2000). Comparison of the laminar distribution of input from areas 17 and 18 of the visual cortex to the lateral geniculate nucleus of the cat. J. Neurosci. 20, 845-853.

Murphy, P. C., Uhlrich, D. J., Tamamaki, N., and Sherman, S. M. (1994). Brain-stem modulation of the response properties of cells in the cat's perigeniculate nucleus. Vis. Neurosci. 11, 781-791. doi: 10.1017/S0952523800003084

Négyessy, L., Hámori, J., and Bentivoglio, M. (1998). Contralateral cortical projection to the mediodorsal thalamic nucleus: origin and synaptic organization in the rat. Neuroscience 84, 741-753. doi: 10.1016/S0306-4522(97) 00559-9 
Niswender, C. M., and Conn, P. J. (2010). Metabotropic glutamate receptors: physiology, pharmacology, and disease. Annu. Rev. Pharmacol. Toxicol. 50, 295-322. doi: 10.1146/annurev.pharmtox.011008.145533

Nothias, F., Onteniente, B., Roudier, F., and Peschanksi, M. (1988). Immunocytochemical study of serotoninergic and noradrenergic innervation of the ventrobasal complex of the rat thalamus. Neurosci. Lett. 95, 59-63. doi: 10.1016/0304-3940(88)90632-5

Ojima, H. (1994). Terminal morphology and distribution of corticothalamic fibers originating from layers 5 and 6 of cat primary auditory cortex. Cereb. Cortex 4 , 646-663. doi: 10.1093/cercor/4.6.646

Olsen, S. R., Bortone, D. S., Adesnik, H., and Scanziani, M. (2012). Gain control by layer six in cortical circuits of vision. Nature 483, 47-52. doi: 10.1038/nature10835

Pais-Vieira, M., Lebedev, M. A., Wiest, M. C., and Nicolelis, M. A. L. (2013). Simultaneous top-down modulation of the primary somatosensory cortex and thalamic nuclei during active tactile discrimination. J. Neurosci. 33, 4076-4093. doi: 10.1523/JNEUROSCI.1659-12.2013

Pape, H. C., and McCormick, D. A. (1989). Noradrenaline and serotonin selectively modulate thalamic burst firing by enhancing a hyperpolarization-activated cation current. Nature 340, 715-718. doi: 10.1038/340715a0

Paré, D., Smith, Y., Parent, A., and Steriade, M. (1988). Projections of brainstem core cholinergic and non-cholinergic neurons of cat to intralaminar and reticular thalamic nuclei. Neuroscience 25, 69-86. doi: 10.1016/0306-4522(88) 90007-3

Parent, A., Paré, D., Smith, Y., and Steriade, M. (1988). Basal forebrain cholinergic and noncholinergic projections to the thalamus and brainstem in cats and monkeys. J. Comp. Neurol. 277, 281-301. doi: 10.1002/cne.902770209

Parent, M., and Descarries, L. (2008). Acetylcholine innervation of the adult rat thalamus: distribution and ultrastructural features in dorsolateral geniculate, parafascicular, and reticular thalamic nuclei. J. Comp. Neurol. 511, 678-691. doi: $10.1002 / \mathrm{cne} .21868$

Pasik, P., Pasik, T., and Holstein, G. R. (1988). Serotonin-immunoreactivity in the monkey lateral geniculate nucleus. Exp. Brain Res. 69, 662-666. doi: 10.1007/BF00247318

Paxinos, G., and Watson, C. (2004). The Rat Brain in Stereotaxic Coordinates-The New Coronal Set, 5th Edn. San Diego, CA: Academic Press.

Petrof, I., Viaene, A. N., and Sherman, S. M. (2012). Two populations of corticothalamic and interareal corticocortical cells in the subgranular layers of the mouse primary sensory cortices. J. Comp. Neurol. 520, 1678-1686. doi: $10.1002 /$ cne. 23006

Picciotto, M. R., Higley, M. J., and Mineur, Y. S. (2012). Acetylcholine as a neuromodulator: cholinergic signaling shapes nervous system function and behavior Neuron 76, 116-129. doi: 10.1016/j.neuron.2012.08.036

Pifl, C., Hornykiewicz, O., Blesa, J., Adánez, R., Cavada, C., and Obeso, J. A. (2013). Reduced noradrenaline, but not dopamine and serotonin in motor thalamus of the MPTP primate: relation to severity of parkinsonism. J. Neurochem. 125, 657-662. doi: 10.1111/jnc. 12162

Piggott, M. A., Ballard, C. G., Dickinson, H. O., McKeith, I. G., Perry, R. H., and Perry, E. K. (2007). Thalamic D2 receptors in dementia with Lewy bodies, Parkinson's disease, and Parkinson's disease dementia. Int. J. Neuropsychopharmacol. 10, 231244. doi: $10.1017 /$ S146114570600647X

Pinto, A., Jankowski, M., and Sesack, S. R. (2003). Projections from the paraventricular nucleus of the thalamus to the rat prefrontal cortex and nucleus accumbens shell: ultrastructural characteristics and spatial relationships with dopamine afferents. J. Comp. Neurol. 459, 142-155. doi: 10.1002/cne.10596

Prasad, J. A., Macgregor, E. M., and Chudasama, Y. (2013). Lesions of the thalamic reuniens cause impulsive but not compulsive responses. Brain Struct. Funct. 218, 85-96. doi: 10.1007/s00429-012-0378-5

Price, J. L., and Slotnick, B. M. (1983). Dual olfactory representation in the rat thalamus: an anatomical and electrophysiological study. J. Comp. Neurol. 215, 63-77. doi: 10.1002/cne.902150106

Purvis, C. C., and Duncan, M. J. (1997). Discrete thalamic lesions attenuate winter adaptations and increase body weight. Am. J. Physiol. 273, R226-R235.

Raczkowski, D., Hamos, J. E., and Sherman, S. M. (1988). Synaptic circuitry of physiologically identified W-cells in the cat's dorsal lateral geniculate nucleus. J. Neurosci. 8, 31-48.

Ramcharan, E. J., Gnadt, J. W., and Sherman, S. M. (2005). Higher-order thalamic relays burst more than first-order relays. Proc. Natl. Acad. Sci. U.S.A. 102, 12236 12241. doi: $10.1073 /$ pnas. 0502843102
Reichova, I., and Sherman, S. M. (2004). Somatosensory corticothalamic projections: distinguishing drivers from modulators. J. Neurophysiol. 92, 2185-2197. doi: 10.1152/jn.00322.2004

Rieck, R. W., Ansari, M. S., Whetsell, W. O. Jr., Deutch, A. Y., and Kessler, R. M. (2004). Distribution of dopamine D2-like receptors in the human thalamus: autoradiographic and PET studies. Neuropsychopharmacology 29, 362-372. doi: 10.1038/sj.npp. 1300336

Risold, P. Y., Thompson, R. H., and Swanson, L. W. (1997). The structural organization of connections between hypothalamus and cerebral cortex. Brain Res. Brain Res. Rev. 24, 197-254. doi: 10.1016/S0165-0173(97)00007-6

Rivadulla, C., Martínez, L. M., Varela, C., and Cudeiro, J. (2002). Completing the corticofugal loop: a visual role for the corticogeniculate type 1 metabotropic glutamate receptor. J. Neurosci. 22, 2956-2962.

Robson, J. A. (1983). The morphology of corticofugal axons to the dorsal lateral geniculate nucleus in the cat. J. Comp. Neurol. 216, 89-103. doi: $10.1002 / \mathrm{cne} .902160108$

Rockland, K. S. (1996). Two types of corticopulvinar terminations: round (type 2) and elongate (type 1). J. Comp. Neurol. 368, 57-87. doi: 10.1002/(SICI)10969861(19960422)368:1<57::AID-CNE5>3.0.CO;2-J

Saalmann, Y. B., Pinsk, M. A., Wang, L., Li, X., and Kastner, S. (2012). The pulvinar regulates information transmission between cortical areas based on attention demands. Science 337, 753-756. doi: 10.1126/science.1223082

Sakurai, T. (2007). The neural circuit of orexin (hypocretin): maintaining sleep and wakefulness. Nat. Rev. Neurosci. 8, 171-181. doi: 10.1038/nrn2092

Salt, T. E., and Turner, J. P. (1998). Modulation of sensory inhibition in the ventrobasal thalamus via activation of group II metabotropic glutamate receptors by 2R,4R-aminopyrrolidine-2,4-dicarboxylate. Exp. Brain Res. 121, 181-185. doi: $10.1007 / \mathrm{s} 002210050450$

Sánchez-González, M. A., García-Cabezas, M. A., Rico, B., and Cavada, C. (2005). The primate thalamus is a key target for brain dopamine. J. Neurosci. 25, 60766083. doi: 10.1523/JNEUROSCI.0968-05.2005

Saper, C. B. (1984). Organization of cerebral cortical afferent systems in the rat. II. Magnocellular basal nucleus. J. Comp. Neurol. 222, 313-342. doi: $10.1002 /$ cne. 902220302

Saper, C. B., and Loewy, A. D. (1980). Efferent connections of the parabrachial nucleus in the rat. Brain Res. 197, 291-317. doi: 10.1016/0006-8993(80) 91117-8

Scharfman, H. E., Lu, S. M., Guido, W., Adams, P. R., and Sherman, S. M. (1990). $\mathrm{N}$-methyl-D-aspartate receptors contribute to excitatory postsynaptic potentials of cat lateral geniculate neurons recorded in thalamic slices. Proc. Natl. Acad. Sci. U.S.A. 87, 4548-4552. doi: 10.1073/pnas.87.12.4548

Schiff, N. D., Giacino, J. T., Kalmar, K., Victor, J. D., Baker, K., Gerber, M., et al. (2007). Behavioural improvements with thalamic stimulation after severe traumatic brain injury. Nature 448, 600-603. doi: 10.1038/nature 06041

Semba, K., Reiner, P. B., and Fibiger, H. C. (1990). Single cholinergic mesopontine tegmental neurons project to both the pontine reticular formation and the thalamus in the rat. Neuroscience 38, 643-654. doi: 10.1016/0306-4522(90) 90058-C

Sherman, S. M. (2001). Tonic and burst firing: dual modes of thalamocortical relay. Trends Neurosci. 24, 122-126. doi: 10.1016/S0166-2236(00)01714-8

Sherman, S. M., and Guillery, R. W. (1998). On the actions that one nerve cell can have on another: distinguishing "drivers" from "modulators." Proc. Natl. Acad. Sci. U.S.A. 95, 7121-7126. doi: 10.1073/pnas.95.12.7121

Shiromani, P. J., Floyd, C., and Velázquez-Moctezuma, J. (1990). Pontine cholinergic neurons simultaneously innervate two thalamic targets. Brain Res. 532, 317-322. doi: 10.1016/0006-8993(90)91774-B

Sillito, A. M., Cudeiro, J., and Jones, H. E. (2006). Always returning: feedback and sensory processing in visual cortex and thalamus. Trends Neurosci. 29, 307-316. doi: 10.1016/j.tins.2006.05.001

Sillito, A. M., Kemp, J. A., and Berardi, N. (1983). The cholinergic influence on the function of the cat dorsal lateral geniculate nucleus (dLGN). Brain Res. 280, 299-307. doi: 10.1016/0006-8993(83)90059-8

Simpson, K. L., Altman, D. W., Wang, L., Kirifides, M. L., Lin, R. C., and Waterhouse, B. D. (1997). Lateralization and functional organization of the locus coeruleus projection to the trigeminal somatosensory pathway in rat. J. Comp. Neurol. 385, 135-147. doi: 10.1002/(SICI)1096-9861(19970818)385:1<135::AIDCNE8 $>3.0 . \mathrm{CO} ; 2-3$ 
Simpson, K. L., Waterhouse, B. D., and Lin, R. C. (1999). Origin, distribution, and morphology of galaninergic fibers in the rodent trigeminal system. J. Comp. Neurol. 411, 524-534. doi: 10.1002/(SICI)1096-9861(19990830)411:3<524::AIDCNE13>3.0.CO;2-X

Simpson, K. L., Waterhouse, B. D., and Lin, R. C. S. (2003). Differential expression of nitric oxide in serotonergic projection neurons: neurochemical identification of dorsal raphe inputs to rodent trigeminal somatosensory targets. J. Comp. Neurol. 466, 495-512. doi: 10.1002/cne.10912

Sittig, N., and Davidowa, H. (2001). Histamine reduces firing and bursting of anterior and intralaminar thalamic neurons and activates striatal cells in anesthetized rats. Behav. Brain Res. 124, 137-143. doi: 10.1016/S0166-4328(01) 00223-6

Smith, Y., Bennett, B. D., Bolam, J. P., Parent, A., and Sadikot, A. F. (1994). Synaptic relationships between dopaminergic afferents and cortical or thalamic input in the sensorimotor territory of the striatum in monkey. J. Comp. Neurol. 344, 1-19. doi: 10.1002/cne.903440102

Smith, Y., Paré, D., Deschênes, M., Parent, A., and Steriade, M. (1988). Cholinergic and non-cholinergic projections from the upper brainstem core to the visual thalamus in the cat. Exp. Brain Res. 70, 166-180.

Smith, Y., Raju, D., Nanda, B., Pare, J. F., Galvan, A., and Wichmann, T. (2009). The thalamostriatal systems: anatomical and functional organization in normal and parkinsonian states. Brain Res. Bull. 78, 60-68. doi: 10.1016/j.brainresbull.2008.08.015

Sofroniew, M. V., Priestley, J. V., Consolazione, A., Eckenstein, F., and Cuello, A. C. (1985). Cholinergic projections from the midbrain and pons to the thalamus in the rat, identified by combined retrograde tracing and choline acetyltransferase immunohistochemistry. Brain Res. 329, 213-223. doi 10.1016/0006-8993(85)90527-X

Spreafico, R., Amadeo, A., Angoscini, P., Panzica, F., and Battaglia, G. (1993). Branching projections from mesopontine nuclei to the nucleus reticularis and related thalamic nuclei: a double labelling study in the rat. J. Comp. Neurol. 336, 481-492. doi: 10.1002/cne.903360402

Steriade, M., Paré, D., Parent, A., and Smith, Y. (1988). Projections of cholinergic and non-cholinergic neurons of the brainstem core to relay and associational thalamic nuclei in the cat and macaque monkey. Neuroscience 25, 47-67. doi 10.1016/0306-4522(88)90006-1

Strakhova, M. I., Nikkel, A. L., Manelli, A. M., Hsieh, G. C., Esbenshade, T. A., Brioni, J. D., et al. (2009). Localization of histamine H4 receptors in the central nervous system of human and rat. Brain Res. 1250, 41-48. doi 10.1016/j.brainres.2008.11.018

Sun, Y.-G., and Beierlein, M. (2011). Receptor saturation controls short-term synaptic plasticity at corticothalamic synapses. J. Neurophysiol. 105, 2319-2329. doi: 10.1152/jn.00942.2010

Swanson, L. W., and Hartman, B. K. (1975). The central adrenergic system. An immunofluorescence study of the location of cell bodies and their efferent connections in the rat utilizing dopamine-beta-hydroxylase as a marker. J. Comp. Neurol. 163, 467-505. doi: 10.1002/cne.901630406

Takahashi, K., Lin, J.-S., and Sakai, K. (2006). Neuronal activity of histaminergic tuberomammillary neurons during wake-sleep states in the mouse. J. Neurosci. 26, 10292-10298. doi: 10.1523/JNEUROSCI.2341-06.2006

Temereanca, S., and Simons, D. J. (2004). Functional topography of corticothalamic feedback enhances thalamic spatial response tuning in the somatosensory whisker/barrel system. Neuron 41, 639-651. doi: 10.1016/S0896-6273(04) 00046-7

Theyel, B. B., Llano, D. A., and Sherman, S. M. (2010). The corticothalamocortical circuit drives higher-order cortex in the mouse. Nat. Neurosci. 13, 84-88. doi: $10.1038 / \mathrm{nn} .2449$

Thomson, A. M. (2010). Neocortical layer 6, a review. Front. Neuroanat. 4:13. doi: 10.3389/fnana.2010.00013

Turner, J. P., and Salt, T. E. (1999). Group III metabotropic glutamate receptors control corticothalamic synaptic transmission in the rat thalamus in vitro. J. Physiol. (Lond.) 519(Pt 2), 481-491. doi: 10.1111/j.1469-7793.1999.0481m.x

Turner, J. P., and Salt, T. E. (2000). Synaptic activation of the group I metabotropic glutamate receptor mGlul on the thalamocortical neurons of the rat dorsal lateral geniculate nucleus in vitro. Neuroscience 100, 493-505. doi: 10.1016/S03064522(00)00280-3

Turner, J. P., and Salt, T. E. (2003). Group II and III metabotropic glutamate receptors and the control of the nucleus reticularis thalami input to rat thalamocortical neurones in vitro. Neuroscience 122, 459-469. doi: 10.1016/j.neuroscience.2003.08.014

Ueda, S., and Sano, Y. (1986). Distributional pattern of serotonin-immunoreactive nerve fibers in the lateral geniculate nucleus of the rat, cat and monkey (Macaca fuscata). Cell Tissue Res. 243, 249-253. doi: 10.1007/BF00251038

Uhlrich, D. J., Cucchiaro, J. B., and Sherman, S. M. (1988). The projection of individual axons from the parabrachial region of the brain stem to the dorsal lateral geniculate nucleus in the cat. J. Neurosci. 8, 4565-4575.

Uhlrich, D. J., Manning, K. A., and Pienkowski, T. P. (1993). The histaminergic innervation of the lateral geniculate complex in the cat. Vis. Neurosci. 10, 225-235. doi: $10.1017 /$ S0952523800003631

Uhlrich, D. J., Manning, K. A., and Xue, J.-T. (2002). Effects of activation of the histaminergic tuberomammillary nucleus on visual responses of neurons in the dorsal lateral geniculate nucleus. J. Neurosci. 22, 1098-1107.

Van Horn, S. C., and Sherman, S. M. (2007). Fewer driver synapses in higher order than in first order thalamic relays. Neuroscience 146, 463-470. doi: 10.1016/j.neuroscience.2007.01.026

Varela, C. (2013). The gating of neocortical information by modulators. J. Neurophysiol. 109, 1229-1232. doi: 10.1152/jn.00701.2012

Varela, C., and Sherman, S. M. (2007). Differences in response to muscarinic activation between first and higher order thalamic relays. J. Neurophysiol. 98, 3538-3547. doi: 10.1152/jn.00578.2007

Varela, C., and Sherman, S. M. (2009). Differences in response to serotonergic activation between first and higher order thalamic nuclei. Cereb. Cortex 19, 17761786. doi: 10.1093/cercor/bhn208

Varela, C., Kumar, S., Yang, J. Y., and Wilson, M. A. (2014). Anatomical substrates for direct interactions between hippocampus, medial prefrontal cortex, and the thalamic nucleus reuniens. Brain Struct. Funct. 219, 911-929. doi: 10.1007/s00429-013-0543-5

Vertes, R. P. (1991). A PHA-L analysis of ascending projections of the dorsal raphe nucleus in the rat. J. Comp. Neurol. 313, 643-668. doi: 10.1002/cne.903130409

Vertes, R. P., Fortin, W. J., and Crane, A. M. (1999). Projections of the median raphe nucleus in the rat. J. Comp. Neurol. 407, 555-582. doi: 10.1002/(SICI) 10969861(19990517)407:4<555::AID-CNE7>3.0.CO;2-E

Vertes, R. P., Linley, S. B., Groenewegen, H. J., and Witter, M. P. (2014). “Thalamus," in The Rat Nervous System, 4th Edn, ed. G. Paxinos (San Diego, CA: Academic Press).

Vertes, R. P., Linley, S. B., and Hoover, W. B. (2010). Pattern of distribution of serotonergic fibers to the thalamus of the rat. Brain Struct. Funct. 215, 1-28. doi: 10.1007/s00429-010-0249-x

Viaene, A. N., Petrof, I., and Sherman, S. M. (2013). Activation requirements for metabotropic glutamate receptors. Neurosci. Lett. 541, 67-72. doi: 10.1016/j.neulet.2013.02.004

Vincent, S. R., Staines, W. A., McGeer, E. G., and Fibiger, H. C. (1980). Transmitters contained in the efferents of the habenula. Brain Res. 195, 479-484. doi: 10.1016/0006-8993(80)90084-0

Vogt, B. A., Hof, P. R., Friedman, D. P., Sikes, R. W., and Vogt, L. J. (2008). Norepinephrinergic afferents and cytology of the macaque monkey midline, mediodorsal, and intralaminar thalamic nuclei. Brain Struct. Funct. 212, 465-479. doi: 10.1007/s00429-008-0178-0

Wang, B., Gonzalo-Ruiz, A., Morte, L., Campbell, G., and Lieberman, A. R. (1999). Immunoelectron microscopic study of glutamate inputs from the retrosplenial granular cortex to identified thalamocortical projection neurons in the anterior thalamus of the rat. Brain Res. Bull. 50, 63-76. doi: 10.1016/S03619230(99)00092-1

Wang, W., Jones, H. E., Andolina, I. M., Salt, T. E., and Sillito, A. M. (2006). Functional alignment of feedback effects from visual cortex to thalamus. Nat. Neurosci. 9, 1330-1336. doi: 10.1038/nn1768

Williams, S. R., and Stuart, G. J. (2000). Action potential backpropagation and somato-dendritic distribution of ion channels in thalamocortical neurons. J. Neurosci. 20, 1307-1317.

Wilson, J. R., Friedlander, M. J., and Sherman, S. M. (1984). Fine structural morphology of identified X-and Y-cells in the cat's lateral geniculate nucleus. Proc. $R$. Soc. Lond. B Biol. Sci. 221, 411-436. doi: 10.1098/rspb.1984.0042

Wilson, J. R., Manning, K. A., Forestner, D. M., Counts, S. E., and Uhlrich, D. J. (1999). Comparison of cholinergic and histaminergic axons in the lateral geniculate complex of the macaque monkey. Anat. Rec. 255, 295-305. doi: 10.1002/(SICI)1097-0185(19990701)255:3<295::AID-AR5>3.0.CO;2-Q 
Woolf, N. J., and Butcher, L. L. (1986). Cholinergic systems in the rat brain: III. Projections from the pontomesencephalic tegmentum to the thalamus, tectum, basal ganglia, and basal forebrain. Brain Res. Bull. 16, 603-637. doi: 10.1016/03619230(86)90134-6

Xu, W., and Südhof, T. C. (2013). A neural circuit for memory specificity and generalization. Science 339, 1290-1295. doi: 10.1126/science.1229534

Zhao, Y., Kerscher, N., Eysel, U., and Funke, K. (2001). Changes of contrast gain in cat dorsal lateral geniculate nucleus by dopamine receptor agonists. Neuroreport 12, 2939-2945. doi: 10.1097/00001756-200109170-00037

Zhao, Y., Kerscher, N., Eysel, U., and Funke, K. (2002). D1 and D2 receptor-mediated dopaminergic modulation of visual responses in cat dorsal lateral geniculate nucleus. J. Physiol. (Lond.) 539, 223-238. doi: 10.1113/jphysiol.2001.012721

Zhu, J., and Heggelund, P. (2001). Muscarinic regulation of dendritic and axonal outputs of rat thalamic interneurons: a new cellular mechanism for uncoupling distal dendrites. J. Neurosci. 21, 1148-1159.

Zhu, J. J., and Uhlrich, D. J. (1997). Nicotinic receptor-mediated responses in relay cells and interneurons in the rat lateral geniculate nucleus. Neuroscience 80, 191202. doi: 10.1016/S0306-4522(97)00095-X
Zhu, J. J., and Uhlrich, D. J. (1998). Cellular mechanisms underlying two muscarinic receptor-mediated depolarizing responses in relay cells of the rat lateral geniculate nucleus. Neuroscience 87, 767-781. doi: 10.1016/S0306-4522(98)00209-7

Conflict of Interest Statement: The author declares that the research was conducted in the absence of any commercial or financial relationships that could be construed as a potential conflict of interest.

Received: 16 March 2014; accepted: 07 June 2014; published online: 24 June 2014.

Citation: Varela C (2014) Thalamic neuromodulation and its implications for executive networks. Front. Neural Circuits 8:69. doi: 10.3389/fncir.2014.00069

This article was submitted to the journal Frontiers in Neural Circuits.

Copyright (C) 2014 Varela. This is an open-access article distributed under the terms of the Creative Commons Attribution License (CC BY). The use, distribution or reproduction in other forums is permitted, provided the original author(s) or licensor are credited and that the original publication in this journal is cited, in accordance with accepted academic practice. No use, distribution or reproduction is permitted which does not comply with these terms. 